\title{
Carbonate Adsorption to Ferrihydrite: Competitive Interaction with Phosphate for Use in Soil Systems
}

\author{
Juan C. Mendez* ${ }^{*}$ and Tjisse Hiemstra
}

Soil Chemistry and Chemical Soil Quality Group, Wageningen University, 6708 PB, Wageningen, The Netherlands

Supporting Information

ABSTRACT: Carbonate $\left(\mathrm{CO}_{3}\right)$ interacts with $\mathrm{Fe}-(\mathrm{hydr})$ oxide nanoparticles, affecting the availability and geochemical cycle of other important oxyanions in nature. Here, we studied the carbonate-phosphate interaction in closed systems with freshly prepared ferrihydrite $(\mathrm{Fh})$, using batch experiments that cover a wide range of $\mathrm{pH}$ values, ionic strength, and $\mathrm{CO}_{3}$ and $\mathrm{PO}_{4}$ concentrations. The surface speciation of $\mathrm{CO}_{3}$ has been assessed by interpreting the ion competition with the Charge Distribution (CD) model, using CD coefficients derived from $\mathrm{MO} / \mathrm{DTF}$ optimized geometries. Adsorption of $\mathrm{CO}_{3}$ occurs predominately via formation of bidentate innersphere complexes, either $(\equiv \mathrm{FeO})_{2} \mathrm{CO}$ or $(\equiv \mathrm{FeO})_{2} \mathrm{CO} \cdot \cdot \mathrm{Na}^{+}$. The latter complex is electrostatically promoted at high $\mathrm{pH}$ and in the presence of adsorbed $\mathrm{PO}_{4}$. Additionally, a minor complex is present at high $\mathrm{CO}_{3}$ loadings. The $\mathrm{CD}$ model, solely parametrized by measuring the $\mathrm{pH}$-dependent $\mathrm{PO}_{4}$ adsorption as a function of the $\mathrm{CO}_{3}$ concentration, successfully predicts the $\mathrm{CO}_{3}$ adsorption to $\mathrm{Fh}$ in single-ion systems. The adsorption affinity of $\mathrm{CO}_{3}$ to $\mathrm{Fh}$ is higher than to goethite, particularly at high $\mathrm{pH}$ and $\mathrm{CO}_{3}$ loadings due to the enhanced formation $(\equiv \mathrm{FeO})_{2} \mathrm{CO} \cdot \cdot \mathrm{Na}^{+}$. The $\mathrm{PO}_{4}$ adsorption isotherm in $0.5 \mathrm{M} \mathrm{NaHCO} 3 \mathrm{can}$ be well described, being relevant for assessing the reactive surface area of the natural oxide fraction with soil extractions and $\mathrm{CD}$ modeling. Additionally, we have evaluated the enhanced Fh solubility due to $\mathrm{Fe}(\mathrm{III})-\mathrm{CO}_{3}$ complex formation and resolved a new species $\left(\mathrm{Fe}\left(\mathrm{CO}_{3}\right)_{2}(\mathrm{OH})_{2}{ }^{3-}(\mathrm{aq})\right)$, which is dominant in closed systems at high $\mathrm{pH}$. The measured solubility of our Fh agrees with the size-dependent solubility predicted using the surface Gibbs free energy of Fh.

KEYWORDS: ferrihydrite, goethite, nanoparticles, ion adsorption, surface complexation, competition, CD model, solubility

\section{INTRODUCTION}

The adsorption of ions to the natural Fe-(hydr)oxides of soils is a key process that regulates the bioavailability, toxicity, and mobility of specific nutrients and contaminants in the environment. ${ }^{1}$ Particularly, understanding the interaction between $\mathrm{Fe}$-(hydr)oxide nanoparticles (FeNPs) and oxyanions such as phosphate $\left(\mathrm{PO}_{4}{ }^{3-}\right)$, sulfate $\left(\mathrm{SO}_{4}{ }^{2-}\right)$, silicate $\left(\mathrm{SiO}_{4}{ }^{4-}\right)$, and arsenate $\left(\mathrm{AsO}_{4}{ }^{3-}\right)$ is of great relevance as its behavior varies under a wide range of environmental conditions. ${ }^{2-6}$ Moreover, recent developments in nanotechnology have shown promising results for the application of engineered FeNPs in a series of environmental and industrial cleanup applications, such as drinking and wastewater treatment. ${ }^{7-9}$

In relation to the ion adsorption capacity, ferrihydrite $(\mathrm{Fh})$ is one of the most reactive FeNPs. The large reactivity of Fh is due to its high specific surface area (SSA $\geq 600 \mathrm{~m}^{2} \mathrm{~g}^{-1}$ ) and high density of reactive surface groups. ${ }^{10,11} \mathrm{Fh}$ is ubiquitously present in terrestrial and aquatic systems ${ }^{12,13}$ and, from the thermodynamic perspective, it is the most stable $\mathrm{Fe}$-(hydr)oxide at the nanometer scale. ${ }^{14}$ Therefore, the study of the fundamental processes that regulate the interaction of ions with $\mathrm{Fh}$ is essential to understand and predict the adsorption behavior of these ions in a variety of systems.
Dissolved inorganic carbon, hereinafter called dissolved carbonate $\left(\mathrm{CO}_{3}\right)$, is another ubiquitous component in terrestrial and aquatic systems. The concentration of $\mathrm{CO}_{3}$ in natural systems such as rivers and groundwater ranges over about 2 orders of magnitude $(\sim 0.1-10 \mathrm{mM}) .^{15,16}$ An important property of $\mathrm{CO}_{3}$ is its capacity to interact with the mineral surfaces of Fe-(hydr)oxides, ${ }^{17,18}$ affecting the solidsolution partitioning of a whole suite of important ions in the environment, ${ }^{19-28}$ including $\mathrm{PO}_{4}{ }^{29,30}$

From an environmental perspective, quantifying the $\mathrm{CO}_{3}-$ $\mathrm{PO}_{4}$ interaction on the surfaces of the $\mathrm{Fe}$-(hydr)oxides is important for understanding the reactivity of the natural oxide fraction. This aspect is essential for assessing the fate of nutrients and pollutants in the environment with Surface Complexation Modeling (SCM). The $\mathrm{CO}_{3}-\mathrm{PO}_{4}$ interaction has been previously used to assess the reactive surface area (RSA) of soil samples. ${ }^{31}$ In that approach, the $\mathrm{PO}_{4}$ buffer capacity of soils is measured by equilibrating the soil with a 0.5 $\mathrm{M} \mathrm{NaHCO}$ solution $(\mathrm{pH}=8.5)$ at different soil-to-solution

Received: October 18, 2018

Revised: November 30, 2018

Accepted: December 2, 2018

Published: December 3, 2018 
ratios. The resulting desorption isotherm has been interpreted with a SCM that was calibrated for the $\mathrm{CO}_{3}-\mathrm{PO}_{4}$ interaction with goethite $(\alpha-\mathrm{FeOOH})$. This material was chosen because of the existence of an internally consistent database with intrinsic adsorption constants. However, the application of this methodology to field samples revealed that the natural oxide fraction of top soils is dominated by nanoparticles $(d \sim 2-10$ $\mathrm{nm}$ ) with a corresponding high specific surface area (SSA 200-1200 $\left.\mathrm{m}^{2} \mathrm{~g}^{-1}\right)$. It suggests that $\mathrm{Fh}$, rather than wellcrystallized goethite, may be a better proxy for the natural oxide fraction in top soils. ${ }^{31}$

To date, no information is available about the competitive interaction of $\mathrm{CO}_{3}$ and $\mathrm{PO}_{4}$ at the surface of $\mathrm{Fh}$. In addition, only a single data set is available in the literature with respect to $\mathrm{CO}_{3}$ adsorption in monocomponent systems with $\mathrm{Fh}^{24}$ These data have been collected using ${ }^{14} \mathrm{C}$ dating, assuming no other source of $\mathrm{CO}_{3}$ in the system than added. Moreover, the adsorption was only studied at very low concentrations of $\mathrm{CO}_{3}$ ( $\mu \mathrm{M}$ level), which are much below the natural concentration range. The lack of reliable information about the adsorption of $\mathrm{CO}_{3}$ to $\mathrm{Fh}$, in systems with and without $\mathrm{PO}_{4}$ ion competition, underlines the scientific and practical relevance of the present research. Our study has a wide perspective as $\mathrm{CO}_{3}$ is omnipresent in nature and will interfere in many geochemical processes, as mentioned above. ${ }^{6,19-30}$

In the present study, our main objective is to measure the interaction of $\mathrm{CO}_{3}$ with the surfaces of freshly prepared $\mathrm{Fh}$ in a series of batch experiments that cover a wide range of chemical conditions. Since measuring the $\mathrm{CO}_{3}$ adsorption is challenging from an analytical perspective, a significant part of our experimental study will refer to the assessment of the interaction of $\mathrm{CO}_{3}$ with $\mathrm{PO}_{4}$ as a function of $\mathrm{pH}(\sim 7-12)$, ionic strength $(0.05-0.5 \mathrm{M})$, total $\mathrm{CO}_{3}$ concentration (4 $\mathrm{mM}-0.5 \mathrm{M})$, and $\mathrm{PO}_{4}$ loading $\left(0.68-1.48 \mu \mathrm{mol} \mathrm{m}{ }^{-2}\right)$. The interaction of $\mathrm{CO}_{3}$ with $\mathrm{Fh}$ will be parametrized by measuring the competitive effect of this anion in the adsorption of $\mathrm{PO}_{4}$. A similar approach has been used successfully to derive the $\mathrm{CO}_{3}$ interaction with goethite. $^{29}$

The charge distribution (CD) model $^{32}$ will be used to interpret the collected competition data, in combination with state-of-the-art knowledge about the mineral and surface structure of $\mathrm{Fh}^{10,11,33}$ To limit the number of adjustable parameters to one per complex (i.e., $\log K$ ), the $C D$ coefficients will be derived with a bond valence analysis ${ }^{34,35}$ of the optimized geometry of the $\mathrm{CO}_{3}$ surface complexes, obtained with molecular orbital ( $\mathrm{MO})$ calculations, applying density functional theory (DFT).

Since $\mathrm{Fh}$ is a nanoparticle pur sang, most of its properties are size dependent. The molar mass $\left(M_{\text {nano }}\right)$ will increase with smaller particle size ${ }^{11}$ due to the change of the chemical composition $\mathrm{FeO}_{1.4}(\mathrm{OH})_{0.2} \cdot n \mathrm{H}_{2} \mathrm{O}$ by the presence of surface groups, giving rise to a size dependent amount of chemisorbed water $\left(n \mathrm{H}_{2} \mathrm{O}\right)$. This will also lead to a decrease of the mass density $(\rho)$ as this chemisorbed water does contribute more to the volume of the particle than to its mass. ${ }^{36}$ These changes in $M_{\text {nano }}$ and $\rho$ will affect the relation between the specific surface area of Fh and its particle size. The size will also change the capacitance values of the Stern layers used in the electrostatic part of the model. ${ }^{36}$ The size-dependence of the above properties will be considered in our modeling, using a consistent set of equations. ${ }^{36,37}$

In addition to the $\mathrm{CO}_{3}-\mathrm{PO}_{4}$ competition data, the $\mathrm{CO}_{3}-\mathrm{Fh}$ interaction will be studied for single-ion systems. The $\mathrm{CD}$ model, parametrized for the $\mathrm{PO}_{4}-\mathrm{CO}_{3}$ interaction, will be applied to compare the experimental adsorption of $\mathrm{CO}_{3}$ with the model predictions for single-ion systems. With the derived adsorption parameters, we will evaluate the surface speciation of $\mathrm{CO}_{3}$ in $\mathrm{Fh}$ systems as a function of solution conditions such as $\mathrm{pH}$, ionic strength, and anion concentrations. In the last part of the paper, we will compare the $\mathrm{CO}_{3}$ interaction of Fh and goethite and show that the significant differences between both materials can be understood from the difference of the interaction of $\mathrm{Na}^{+}$with adsorbed $\mathrm{CO}_{3}$. This will lead to a strong difference of the competitive behavior of $\mathrm{CO}_{3}$ with $\mathrm{PO}_{4}$ bound by either $\mathrm{Fh}$ or goethite. It will have important implications for assessing the RSA of field soil samples, as we will discuss briefly.

\section{EXPERIMENTAL SECTION}

For all the adsorption experiments, ultrapure water (18.2 M $\Omega$ $\mathrm{cm}$ at $25{ }^{\circ} \mathrm{C},<1 \mathrm{ppb}$ TOC) and chemical reactants of analytical grade were used to prepare the stock solutions and the Fh suspensions. Contact between solutions and air was largely avoided to reduce the interference of atmospheric $\mathrm{CO}_{2(\mathrm{~g})}$ during the adsorption experiments.

2.1. Ferrihydrite Synthesis. Fh suspensions were prepared by fast neutralizing with $0.02 \mathrm{M} \mathrm{NaOH}$ a solution of $\sim 3.7 \mathrm{mM}$ of $\mathrm{Fe}\left(\mathrm{NO}_{3}\right)_{3}$ dissolved in $0.010 \mathrm{M} \mathrm{HNO}_{3}$. Freshly prepared acid and base solutions were always used. The neutralization was initially done at a rate of $\sim 200 \mathrm{~mL} \mathrm{NaOH}$ $\min ^{-1}$ until a $\mathrm{pH}$ of $\sim 3.2$ was reached. More $\mathrm{NaOH}$ solution was subsequently added in $\sim 5 \mathrm{~mL}$ increments until the suspension reached a final stable $\mathrm{pH}$ (over $15 \mathrm{~min}$ ) of $\sim 8.2$ for the binary $\mathrm{CO}_{3}-\mathrm{PO}_{4}$ adsorption experiments, or $\mathrm{pH} \sim 6.0$ for the $\mathrm{CO}_{3}$ adsorption experiments in monocomponent systems. The Fh suspensions were centrifuged at $3500 \mathrm{~g}$ for $45 \mathrm{~min}$, the supernatant was carefully removed, and the settled Fh particles were resuspended in a $0.01 \mathrm{M} \mathrm{NaNO}$ solution. The Fh suspensions were aged at $20{ }^{\circ} \mathrm{C}$ for $4 \mathrm{~h}$ since formation before starting the $\mathrm{CO}_{3}-\mathrm{PO}_{4}$ competition experiments. Due to the relatively low level of added $\mathrm{CO}_{3}$, the results of the adsorption experiments of $\mathrm{CO}_{3}$ in single-ion systems may be particularly sensitive to interference of atmospheric $\mathrm{CO}_{2(\mathrm{~g})}$. Therefore, the Fh suspensions used in these systems were first acidified to $\mathrm{pH}$ $\sim 5.5$ and purged during $24 \mathrm{~h}$ with moist purified $\mathrm{N}_{2(\mathrm{~g})}$ before starting the adsorption experiments. The total $\mathrm{Fe}$ concentration $\left(\mathrm{Fe}_{[\mathrm{T}]}\right)$ of each $\mathrm{Fh}$ suspension was measured by ICPOES in a matrix of $0.8 \mathrm{M} \mathrm{H}_{2} \mathrm{SO}_{4}$. The $\mathrm{Fe}_{[\mathrm{T}]}$ was typically 19.3 $\pm 0.7 \mathrm{mM}$, which is equivalent to $1.90 \pm 0.07 \mathrm{~g} \mathrm{Fh} \mathrm{L}^{-1}$ (for a mean $\mathrm{Fh}$ molar mass of $M_{\text {nano }}=97.6 \mathrm{~g} \mathrm{Fh} \mathrm{mol}^{-1} \mathrm{Fe}$ ). The specific surface area (SSA in $\mathrm{m}^{2} \mathrm{~g}^{-1}$ ) of each Fh suspension was assessed independently by using $\mathrm{PO}_{4}$ as probe ion. ${ }^{37}$ The values of $\mathrm{Fe}_{[\mathrm{T}]}, S S A$, and $M_{\text {nano }}$ corresponding to each $\mathrm{Fh}$ preparation are presented in Table $S-1$ of the Supporting Information (SI).

2.2. Competitive Adsorption Carbonate-Phosphate. The competitive interaction of $\mathrm{CO}_{3}$ with $\mathrm{PO}_{4}$ was experimentally evaluated by determining the adsorption edges of $\mathrm{PO}_{4}$ in a series of closed $\mathrm{Fh}$ systems with different concentrations of both oxyanions. Each individual system was prepared in $50 \mathrm{~mL}$ polypropylene tubes and contained a total volume of $40.0 \mathrm{~mL}$. First, the required volume of ultrapure water and $4 \mathrm{M} \mathrm{NaNO}_{3}$ solution was added into the tubes according to the intended final volume and background electrolyte level. Next, aliquots of 10.0 or $15.0 \mathrm{~mL}$ of the freshly prepared $\mathrm{Fh}$ were pipetted into the tubes and the $\mathrm{pH}$ of 
the suspensions was adjusted by adding acid $\left(\mathrm{HNO}_{3}\right)$ or base $(\mathrm{NaOH})$ solutions, leading to $\mathrm{pH} \sim 6.5-11$. Adsorption systems with $\mathrm{pH}$ values below 6.5 were not prepared to prevent the escape of $\mathrm{HCO}_{3}{ }^{-}$to the atmosphere as $\mathrm{CO}_{2(\mathrm{~g})}$. Finally, volumes of the stock solution of $\mathrm{NaH}_{2} \mathrm{PO}_{4}(0.010 \mathrm{M})$ and $\mathrm{NaHCO}_{3}(0.10$ or $1.0 \mathrm{M})$ were pipetted into the tubes. The $\mathrm{NaHCO}_{3}$ solutions were freshly prepared before each experiment. Total $\mathrm{PO}_{4}$ concentrations $\left(\mathrm{PO}_{4[\mathrm{~T}]}\right)$ of 0.25 and $0.50 \mathrm{mM}$ were used in the systems with a low $\mathrm{Fh}$ content, whereas $\mathrm{PO}_{4[\mathrm{~T}]}$ of 0.50 and $0.75 \mathrm{mM}$ were used in the systems with a high $\mathrm{Fh}$ content. These combinations resulted in systems with a total $\mathrm{PO}_{4}$ loading $\left(\mathrm{PO}_{4(\mathrm{~T})}\right)$ equivalent to 0.68 , 1.07, and $1.48 \mu \mathrm{mol} \mathrm{m}^{-2}$. The total $\mathrm{CO}_{3}$ concentrations $\left(\mathrm{CO}_{3[\mathrm{~T}]}\right)$ varied between $4.0 \mathrm{mM}$ and $0.50 \mathrm{M}$. Most of the experiments were performed at a constant ionic strength of $I=$ $0.50 \mathrm{M}$. Additional experiments were done at $I=0.050$ and $0.10 \mathrm{M}$ for evaluating the effect of different $\mathrm{Na}^{+}$levels on the competitive interaction of $\mathrm{CO}_{3}-\mathrm{PO}_{4}$. A summary of the chemical conditions for each experimental series is presented in Table S-1 of the Supporting Information.

The thus-prepared $\mathrm{CO}_{3}-\mathrm{PO}_{4}$ systems with $\mathrm{Fh}$ were constantly shaken (120 strokes $\mathrm{min}^{-1}$ ) in a conditioned room at $20{ }^{\circ} \mathrm{C}$. After $20 \mathrm{~h}$ of equilibration, the suspensions were centrifuged at $3500 \mathrm{~g}$ for $20 \mathrm{~min}$ to separate the $\mathrm{Fh}$ nanoparticles and the liquid phase. The equilibrium $\mathrm{pH}$ of the solution was measured with a glass electrode, and immediately after this, an aliquot of $10 \mathrm{~mL}$ was taken from the supernatant for chemical analysis. This aliquot was filtered through a 0.45 $\mu \mathrm{m}$ filter and acidified with $\mathrm{HNO}_{3}$ to analyze the total concentration of $\mathrm{P}$ in solution by either ICP-OES or ICP-MS, depending on the final concentration of $\mathrm{P}$. The concentration of $\mathrm{Fe}$ was also measured in the supernatant of a selected number of samples to test if significant dissolution of $\mathrm{Fh}$ occurred during the adsorption experiments, due to the formation of aqueous $\mathrm{Fe}(\mathrm{III})-\mathrm{CO}_{3}$ complexes. ${ }^{38}$

2.3. Carbonate Adsorption in Monocomponent Systems. The adsorption of $\mathrm{CO}_{3}$ in monocomponent systems with $\mathrm{Fh}$ was experimentally evaluated following a similar procedure than used for the binary $\mathrm{CO}_{3}-\mathrm{PO}_{4}$ systems. The $\mathrm{pH}$ of the adsorption systems ranged from $\sim 6.5$ to $\sim 10.5$, and the ionic strength was kept constant at $I=0.10 \mathrm{NaNO}_{3}$. Aliquots of 10, 20, or $30 \mathrm{~mL}$ of $\mathrm{Fh}$ suspension, aged for $24 \mathrm{~h}$, were pipetted into the systems with a final solution volume of $40 \mathrm{~mL}$. The $\mathrm{CO}_{3[\mathrm{~T}]}$ was $1 \mathrm{mM}$, which was added using a freshly prepared $0.010 \mathrm{M} \mathrm{NaHCO}_{3}$ stock solution. The gas-tosolution ratio of the systems was $0.25 \mathrm{~mL} \mathrm{~mL}^{-1}$, which was used in the model calculations to account for the distribution of the total added $\mathrm{CO}_{3}$ over the gas and liquid phases. The samples were equilibrated for $20 \mathrm{~h}$ at $20{ }^{\circ} \mathrm{C}$, and after centrifugation, a volume of $10 \mathrm{~mL}$ of solution was rapidly taken for analysis of the $\mathrm{CO}_{3}$ concentration. The equilibrium $\mathrm{pH}$ was immediately measured in the remaining supernatant. The $\mathrm{CO}_{3}$ concentration in solution was measured with a TOC analyzer, which converts the dissolved inorganic carbon into $\mathrm{CO}_{2(\mathrm{~g})}$ by means of an internal acidification step. The concentration of produced $\mathrm{CO}_{2(\mathrm{~g})}$ is then measured with an IR detector. Internal standard solutions with known concentrations of total dissolved $\mathrm{CO}_{3}$ were also analyzed to verify the accuracy of our measurements. At every moment, maximum care was taken to minimize the escape/intrusion of $\mathrm{CO}_{2(\mathrm{~g})}$ to/from the atmosphere.

2.4. CD Modeling and MO/DFT Calculations. The interaction between $\mathrm{CO}_{3}$ and $\mathrm{PO}_{4}$ at the mineral-solution interface of $\mathrm{Fh}$ has been described using the charge distribution (CD) model $^{32}$ in combination with the extended Stern layer model ${ }^{39}$ that describes the compact part of the electrical double layer (EDL). In this electrostatic model, we have accounted for the effect of the nanosized spherical particles on the capacitance values $\left(C_{1}\right.$ and $\left.C_{2}\right)$ of the inner and outer Stern layers, in relation to the capacitance values of a flat plane. ${ }^{36}$ The types of sites and the corresponding site densities have been derived with a surface structural analysis of $\mathrm{Fh}^{37}$ based on recent insights into the mineral and surface structure of this Fe-(hydr)oxide material. ${ }^{10,11,33}$ Primary charge reactions have been described according to Hiemstra. ${ }^{5} \mathrm{CD}$ model parameters for describing the adsorption of $\mathrm{PO}_{4}$ to $\mathrm{Fh}$ were taken from Hiemstra and $\mathrm{Zhao},{ }^{37}$ whereas the parameters for $\mathrm{CO}_{3}$ have been derived in the present study from modeling the competition experiments with $\mathrm{PO}_{4}$. $\mathrm{CD}$ modeling was done with the software Ecosat, ${ }^{40}$ version 4.9. The adsorption parameters for $\mathrm{CO}_{3}$ were optimized using the program FIT, ${ }^{41}$ version 2.581. The entire set of solution speciation reactions and primary charge reactions used in the modeling are presented respectively in Tables $S-2$ and $S-3$ given in the Supporting Information.

The geometries of the hydrated $\mathrm{CO}_{3}$ complexes were optimized with molecular orbital (MO) calculations, using the Spartan14 parallel of Wavefunction, Inc. Density functional theory (DFT) was applied, using a range of functionals (BP86, B3LYP, EDF1, EDF2, BLYP, $\omega$ P97X-D). For the geometries optimization, we have used $\left(\mathrm{H}_{2} \mathrm{O}\right)_{2} \mathrm{Fe}_{2}(\mathrm{OH})_{6}$ as template with fixed atomic positions ${ }^{42}$ to which a hydrated moiety with $\mathrm{CO}_{3}{ }^{2-}, \mathrm{HCO}_{3}{ }^{-}$, or $\mathrm{NaCO}_{3}{ }^{-}$was attached to form an innersphere complex that was allowed to freely relax. The average $\mathrm{O}-\mathrm{C}$ bond lengths obtained with the different DFT functionals were interpreted with the Brown valence concept. $^{34,35}$ The resulting charge distribution coefficients have been corrected for the electrostatic contribution of water dipole orientation. ${ }^{39}$

\section{RESULTS AND DISCUSSION}

3.1. Dissolution of Ferrihydrite in Carbonate Media. Carbonate may significantly increase the solubility of $\mathrm{Fe}$ (hydr)oxides ${ }^{38,43,44}$ by forming aqueous $\mathrm{Fe}(\mathrm{III})-\mathrm{CO}_{3}$ complexes, particularly above neutral $\mathrm{pH}$. As this may have influence on our interpretation of the $\mathrm{CO}_{3}-\mathrm{PO}_{4}$ adsorption experiments, we have first evaluated the solubility of $\mathrm{Fh}$ in a number of binary $\mathrm{CO}_{3}-\mathrm{PO}_{4}$ adsorption systems by measuring the concentration of $\mathrm{Fe}$ in the supernatant of these systems (Figure 1).

According to Grivé et al., ${ }^{38}$ two aqueous $\mathrm{Fe}(\mathrm{III})-\mathrm{CO}_{3}$ complexes may form in carbonate solutions, i.e. a neutral $\mathrm{FeOHCO}_{3}{ }^{0}$ complex that dominates the $\mathrm{Fe}(\mathrm{III})$ solution speciation at $\mathrm{pH} \sim 4-7$ and a $\mathrm{Fe}\left(\mathrm{CO}_{3}\right)_{3}{ }^{3-}$ complex that controls the $\mathrm{Fe}$ (III) speciation above $\mathrm{pH} 7$. Formation of the latter species leads to a significant increase of the solubility of Fe-(hydr)oxides in open systems with high partial $\mathrm{CO}_{2}$ pressures (Figure S-2). However, such partial pressures are not present in our closed systems because the total concentration of $\mathrm{CO}_{3}$ remains constant with $\mathrm{pH}$, in contrast to the open systems used by Grive et al. ${ }^{38}$ For the latter system, one may calculate the solubility of $\mathrm{Fh}$ as a function of $\mathrm{pH}$, using the above given $\mathrm{Fe}(\mathrm{III})-\mathrm{CO}_{3}$ complexes. Representing $\mathrm{Fh}$ as $\mathrm{Fe}(\mathrm{OH})_{3}(\mathrm{~s})$, the formation reactions of these $\mathrm{Fe}(\mathrm{III})-\mathrm{CO}_{3}$ complexes can be given as 


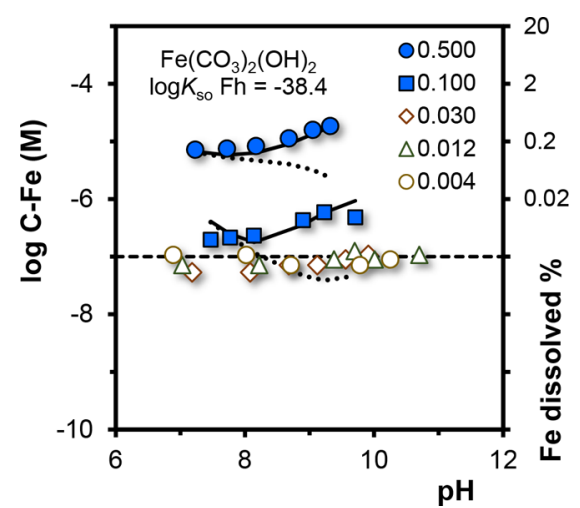

Figure 1. Logarithm of the experimental Fe concentrations (symbols) in the supernatants (left $y$-axis) and percentages of dissolved Fh (right $y$-axis) measured in our binary $\mathrm{CO}_{3}-\mathrm{PO}_{4}-\mathrm{Fh}$ systems as a function of $\mathrm{pH}$ for different $\mathrm{CO}_{3[\mathrm{~T}]}$ with a fixed total concentration of Fe (4.9 $\mathrm{mM})$ and $\mathrm{PO}_{4}(0.25 \mathrm{mM})$ at a constant ionic strength $(I=0.5 \mathrm{M})$. Only the systems with 0.50 and $0.10 \mathrm{M} \mathrm{CO} \mathrm{CO}_{3[\mathrm{~T}]}$ have $\mathrm{Fe}$ concentrations that are clearly above the detection limit (dashed line) of our ICP-MS measurements. This detection limit is relatively high due to the very high electrolyte concentration that requires dilution. Dotted lines are model predictions including only the $\mathrm{Fe}(\mathrm{III})-\mathrm{CO}_{3}$ complexes proposed by Grive et al., ${ }^{38}$ whereas the solid lines are model predictions using additionally $\mathrm{Fe}\left(\mathrm{CO}_{3}\right)_{2}(\mathrm{OH})_{2}{ }^{3-}(\mathrm{aq})$ (See text). The solubility of our Fh was found to be $\log Q=\log \left(\mathrm{Fe}^{3+}\right)$ $+3 \log \left(\mathrm{OH}^{-}\right)=-38.4 \pm 0.1$, which is in line with the solubility calculated for Fh with a mean particle size of $\sim 2.2 \mathrm{~nm}$ and a specific surface area of $765 \mathrm{~m}^{2} \mathrm{~g}^{-1}\left(\log Q_{\mathrm{so}}=-38.2 \pm 0.2\right)$ applying the Ostwald equation with a surface Gibbs free energy of $0.186 \pm 0.01 \mathrm{~J}$ $\mathrm{m}^{-2}$ and an intrinsic (bulk) solubility of $\log K_{\mathrm{so}}=-40.6 \pm 0.1$ as described elsewhere. ${ }^{14}$

$$
\begin{aligned}
& \mathrm{Fe}(\mathrm{OH})_{3}(\mathrm{~s})+\mathrm{HCO}_{3}{ }^{-}(\mathrm{aq})+\mathrm{H}^{+}(\mathrm{aq}) \\
& \Leftrightarrow \mathrm{FeOHCO}_{3}{ }^{0}(\mathrm{aq})+2 \mathrm{H}_{2} \mathrm{O}(\mathrm{l}) \\
& \mathrm{Fe}(\mathrm{OH})_{3}(\mathrm{~s})+3 \mathrm{HCO}_{3}{ }^{-}(\mathrm{aq}) \\
& \Leftrightarrow \mathrm{Fe}\left(\mathrm{CO}_{3}\right)_{3}{ }^{3-}(\mathrm{aq})+3 \mathrm{H}_{2} \mathrm{O}(\mathrm{l})
\end{aligned}
$$

For solutions with a constant concentration of $\mathrm{HCO}_{3}{ }^{-}$, the overall solubility of $\mathrm{Fh}$ will be $\mathrm{pH}$-independent, if the solution speciation of $\mathrm{Fe}$ is dominated by $\mathrm{Fe}\left(\mathrm{CO}_{3}\right)_{3}{ }^{3-}(\mathrm{aq})$. As $\mathrm{HCO}_{3}{ }^{-}(\mathrm{aq})$ gradually transforms into $\mathrm{CO}_{3}{ }^{2-}(\mathrm{aq})$ at high $\mathrm{pH}$, the solubility of $\mathrm{Fh}$ is predicted to decrease (dotted lines in Figure 1), whereas our data show an opposite trend with $\mathrm{pH}$. The difference can be explained by the formation of an additional $\mathrm{Fe}(\mathrm{III})-\mathrm{CO}_{3}$ species. Our experimental data for the dissolved $\mathrm{Fe}$ concentrations can be described by assuming the formation of an extra $\mathrm{Fe}(\mathrm{III})-\mathrm{CO}_{3}$ complex, according to the reaction:

$$
\begin{aligned}
& \mathrm{Fe}(\mathrm{OH})_{3}(\mathrm{~s})+2 \mathrm{HCO}_{3}{ }^{-}(\mathrm{aq}) \\
& \quad \Leftrightarrow \mathrm{Fe}\left(\mathrm{CO}_{3}\right)_{2}(\mathrm{OH})_{2}{ }^{3-}(\mathrm{aq})+\mathrm{H}^{+}(\mathrm{aq})+1 \mathrm{H}_{2} \mathrm{O}(\mathrm{l})
\end{aligned}
$$

The $\log K$ values of reactions $1-3$ are respectively $\log K=$ $24.86 \pm 0.09,24.86 \pm 0.09$, and $31.71 \pm 0.13$. Details on deriving these constants as well as the solubility product of our Fh material can be found in Appendix 5 of the SI.

In Figure 1, the right $y$-axis gives the fraction of the total $\mathrm{Fe}$ that is dissolved in our systems. For the systems with a $\mathrm{CO}_{3[\mathrm{~T}]}$ of $0.50 \mathrm{M}$, less than $\sim 0.5 \%$ of the total $\mathrm{Fe}$ is dissolved at the highest $\mathrm{pH}$. This implies that the effect of $\mathrm{CO}_{3}$ on the dissolution of $\mathrm{Fh}$ is negligible under our experimental conditions, as nearly $100 \%$ of the total $\mathrm{Fe}$ in the systems remains part of the solid phase.

\subsection{Interaction Carbonate-Phosphate in Ferrihydrite} Systems. 3.2.1. Influence of $\mathrm{pH}$ and Carbonate Concentration. Figure 2 presents the adsorption edges of $\mathrm{PO}_{4}$ to $\mathrm{Fh}$ for systems with different $\mathrm{CO}_{3[\mathrm{~T}]}$ at two levels of $\mathrm{PO}_{4(\mathrm{~T})}$ equivalent to 0.68 (a) and 1.07 (b) $\mu \mathrm{mol} \mathrm{m}^{-2}$. The background $\mathrm{Na}^{+}$concentration was kept constant at $0.50 \mathrm{M}$ by adding appropriate amounts of $\mathrm{NaNO}_{3}$. A series of observations can be made focusing on these data. First, with increase of $\mathrm{CO}_{3[\mathrm{~T}]}$, the $\mathrm{PO}_{4}$ adsorption decreases. This illustrates the competition between both ions for the same binding sites at the surfaces of Fh. Second, the percentage of adsorbed $\mathrm{PO}_{4}$ decreases when the solution $\mathrm{pH}$ increases. This $\mathrm{pH}$-dependency is characteristic for oxyanions in general $\left(\mathrm{PO}_{4}{ }^{3-}, \mathrm{AsO}_{4}{ }^{3-}, \mathrm{SO}_{4}{ }^{2-}\right)$ binding to the surfaces of $\mathrm{Fe}$-(hydr)oxides. ${ }^{4-47}$ With increase of $\mathrm{pH}$, the protonated singly $\left(\equiv \mathrm{FeOH}_{2}{ }^{+0.5}\right)$ and triply $\left(\equiv \mathrm{Fe}_{3} \mathrm{OH}^{+0.5}\right)$ coordinated surface groups will gradually release protons. This will lead to a decrease of the electrostatic surface potential and, consequently, to less attraction of the negatively charged $\mathrm{PO}_{4}$ ions by the surface.

Additionally, the adsorption of $\mathrm{PO}_{4}$ to $\mathrm{Fh}$ does not decrease proportionally to the increase of the $\mathrm{CO}_{3[\mathrm{~T}]}$ (Figure 2). This nonproportional effect is related to the higher affinity of $\mathrm{PO}_{4}$ for the adsorption to $\mathrm{Fh}$, in comparison with $\mathrm{CO}_{3}$. A quite high
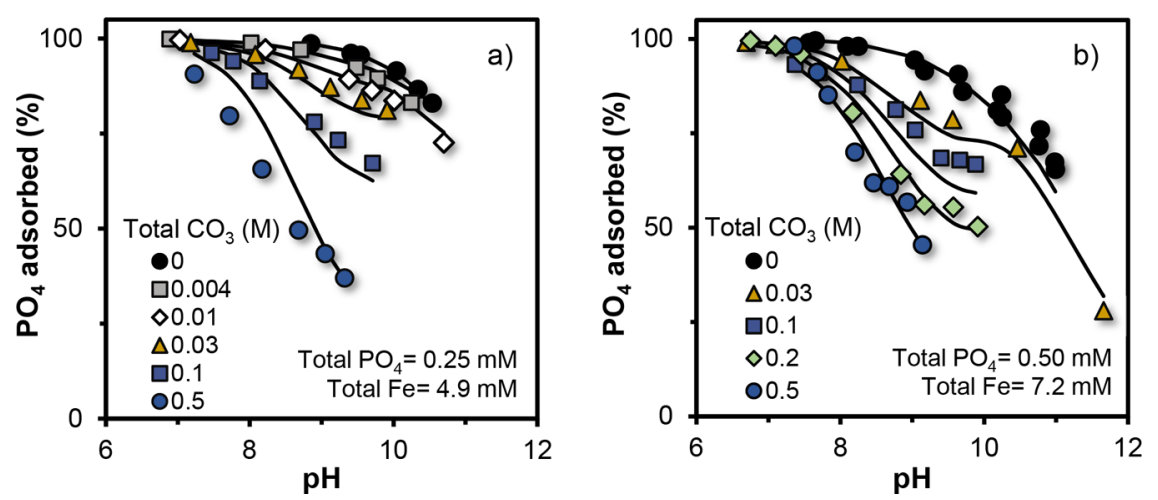

Figure 2. Adsorption edges of the competitive $\mathrm{PO}_{4}$ binding to $\mathrm{Fh}$ in closed $\mathrm{CO}_{3}$ systems at constant ionic strength of $0.50 \mathrm{M}$ created by adding additionally $\mathrm{NaNO}_{3}$. The symbols are experimental results, and the lines are $\mathrm{CD}$ model calculations applying the parameter set of Table 1 . The zero-carbonate system has been used to derive the specific surface area of Fh, being for system (a) 765 and (b) $672 \mathrm{~m}^{2} \mathrm{~g}^{-1}$ at a molar mass of

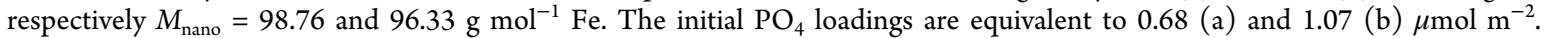



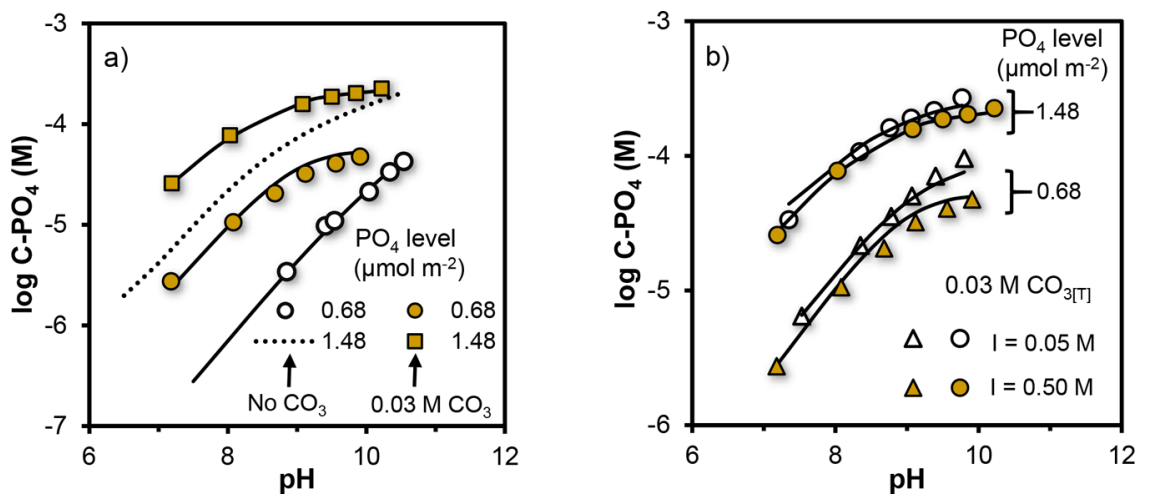

Figure 3. Logarithm of the equilibrium concentration of $\mathrm{PO}_{4}$ as a function of $\mathrm{pH}$ in closed systems with Fh. Symbols are experimental results, and lines are $\mathrm{CD}$ model calculations using the parameter set of Table 1 . The total Fe content was $4.5 \mathrm{mM}$ for all the series, except for the colored triangle series in panel $\mathrm{b}$, whose total Fe concentration was $4.9 \mathrm{mM}$. The calibrated specific surface area of the Fh suspensions used here was SSA = $765 \mathrm{~m}^{2} \mathrm{~g}^{-1}$ at a molar mass of $M_{\text {nano }}=98.76 \mathrm{~g} \mathrm{~mol}^{-1} \mathrm{Fe}$. Panel a shows the effect of the addition of $0.03 \mathrm{M} \mathrm{CO}_{3}$ (colored symbols) on the equilibrium $\mathrm{PO}_{4}$ concentration for systems with two levels of $\mathrm{PO}_{4(\mathrm{~T})}\left(0.68\right.$ and $\left.1.48 \mu \mathrm{mol} \mathrm{PO}_{4} \mathrm{~m}^{-2}\right)$. As reference, the equilibrium concentration of $\mathrm{PO}_{4}$ in monocomponent systems has been measured and/or modeled (open symbols and dotted line). All data correspond to systems with an ionic strength of $0.5 \mathrm{M}$, made by adding additionally $\mathrm{NaNO}_{3}$. Panel b presents the effect of the ionic strength ( $0.05 \mathrm{M}$ for open symbols, $0.5 \mathrm{M}$ for colored symbols) on the equilibrium $\mathrm{PO}_{4}$ concentration for systems with a total $\mathrm{CO}_{3[\mathrm{~T}]}=0.03 \mathrm{M}$ for two initial $\mathrm{PO}_{4}$ loadings, as given.

concentration of $\mathrm{CO}_{3}$ ions is needed before the adsorption of $\mathrm{PO}_{4}$ to $\mathrm{Fh}$ is significantly suppressed. The competitive effect of $\mathrm{CO}_{3}$ on the adsorption of $\mathrm{PO}_{4}$ depends on the relative concentration of both ions in solution $\left(\left[\mathrm{PO}_{4}\right] /\left[\mathrm{PO}_{4}+\mathrm{CO}_{3}\right]\right)$.

The relatively high affinity of $\mathrm{PO}_{4}$ for binding to $\mathrm{Fh}$ can be depicted by constructing a normalized adsorption isotherm for binary $\mathrm{CO}_{3}-\mathrm{PO}_{4}$ systems. In this isotherm, the amount of adsorbed $\mathrm{PO}_{4}$ as well as its solution concentration are presented on a relative scale $(0-100 \%)$ with respect to the total amount adsorbed and total solution concentration of oxyanions $\left(\left[\mathrm{PO}_{4}+\mathrm{CO}_{3}\right]\right)$. The constructed isotherm (Figure S-4) shows that only a small fraction of dissolved $\mathrm{PO}_{4}$ is needed to dominate the oxyanion adsorption onto Fh. This is very different for the adsorption of $\mathrm{PO}_{4}$ in binary systems with a stronger competitor, as for instance $\mathrm{AsO}_{4}$, where the normalized adsorption isotherm is much closer to a $1: 1$ line, as shown in Figure S-4 of the Supporting Information.

3.2.2. Influence of Phosphate Loading and Electrolyte Concentration. Figure 3 a shows the equilibrium concentration of $\mathrm{PO}_{4}$ in solution as a function of $\mathrm{pH}$ for systems that differ in surface loading with $\mathrm{PO}_{4}\left(0.68\right.$ and $\left.1.48 \mu \mathrm{mol} \mathrm{m} \mathrm{m}^{-2}\right)$ in the presence and absence of $\mathrm{CO}_{3}$. Due to the competition with $\mathrm{CO}_{3}$, the equilibrium concentration of $\mathrm{PO}_{4}$ is higher in the systems with $0.03 \mathrm{M} \mathrm{CO}_{3}$ in comparison to the corresponding $\mathrm{PO}_{4}$ monocomponent systems. However, for a given $\mathrm{pH}$, the extent of the $\mathrm{CO}_{3}$ effect depends on the $\mathrm{PO}_{4}$ level in the system. Addition of $0.03 \mathrm{M} \mathrm{CO}_{3[\mathrm{~T}]}$ leads to a larger increase of the $\mathrm{PO}_{4}$ concentration in the systems with the lower initial $\mathrm{PO}_{4}$ loading.

Figure $3 \mathrm{a}$ also shows that $\mathrm{CO}_{3}$ enhances the equilibrium concentration of $\mathrm{PO}_{4}$ more at a lower $\mathrm{pH}$. This is related to the $\mathrm{pH}$ dependency of the $\mathrm{CO}_{3}$ adsorption, reaching a maximum near $\mathrm{pH} \sim 7$, as we will show later in section 3.4.1. This has also been found for goethite ${ }^{16,25}$ and matches qualitatively also with other data obtained for goethite using the same experimental approach. ${ }^{29}$

In Figure $3 b$, the effect of the ionic strength on the competitive interaction between $\mathrm{CO}_{3}$ and $\mathrm{PO}_{4}$ is shown. In general, a rather small effect of the ionic strength is observed, which is consistent with the formation of predominantly innersphere surface complexes for $\mathrm{PO}_{4}{ }^{45,48-50}$ The largest differ- ences are found at high $\mathrm{pH}$ and relatively low loading with $\mathrm{PO}_{4}$.

The increase of the $\mathrm{PO}_{4}$ adsorption with increase of ionic strength can be understood from a better screening of the repulsive interface charge at a higher ionic strength. The trend observed in Figure $3 \mathrm{~b}$ agrees with the ionic strength dependency of the specific adsorption of anions in general as reported for monocomponent systems with $\mathrm{Fh}^{37,45,48}$ The adsorption of $\mathrm{CO}_{3}$ contributes also to this trend as discussed in section 3.3.2.

3.3. Surface Complexation Modeling. In this section, we will explore the main mechanisms of the $\mathrm{CO}_{3}$ adsorption to $\mathrm{Fh}$ by interpreting the results of the competitive $\mathrm{CO}_{3}-\mathrm{PO}_{4}$ adsorption experiments with the $\mathrm{CD}$ model. ${ }^{32} \mathrm{~A}$ similar approach was successfully applied previously by Rahnemaie et al. ${ }^{29}$ for describing the adsorption of $\mathrm{CO}_{3}$ onto goethite.

3.3.1. Surface Structure of Ferrihydrite. Presently, we will apply the multisite ion adsorption model recently developed for Fh. ${ }^{37}$ A surface structural analysis ${ }^{37}$ reveals the presence of two types of reactive surface groups at the surface of $\mathrm{Fh}$, namely singly $\left(\equiv \mathrm{FeOH}^{-1 / 2}\right)$ and the triply $\left(\equiv \mathrm{Fe}_{3} \mathrm{O}^{-1 / 2}\right)$ coordinated groups. The singly coordinated groups are dominantly present having a total site density of $5.8 \pm 0.3$ $\mathrm{nm}^{-2}$ or $9.6 \mu \mathrm{mol} \mathrm{m}{ }^{-2}$. Based on the surface structure, two types of singly coordinated groups are defined: those that only allow the formation of monodentate surface complexes $\left(\equiv \mathrm{FeOH}(\mathrm{a})^{-1 / 2}\right)$ and those that in addition allow the formation of binuclear bidentate surfaces complexes $(\equiv \mathrm{FeOH}$ $(b)^{-1 / 2}$ ) with e.g. $\mathrm{PO}_{4}$ and $\mathrm{AsO}_{4}$ ions. ${ }^{37}$ The site densities of these $\equiv \mathrm{FeOH}(\mathrm{a})^{-1 / 2}$ and $\equiv \mathrm{FeOH}(\mathrm{b})^{-1 / 2}$ groups are $3.0 \pm 0.6$ and $2.8 \pm 0.6 \mathrm{~nm}^{-2}$, respectively. The triply coordinated groups $\left(\equiv \mathrm{Fe}_{3} \mathrm{O}^{-1 / 2}\right)$ do not participate directly in the ligand exchange reactions with oxyanions, but they contribute to the development of primary surface charge. The value for the effective site density of the $\equiv \mathrm{Fe}_{3} \mathrm{O}^{-1 / 2}$ groups $\left(1.4 \pm 0.5 \mathrm{~nm}^{-2}\right)$ has been derived by fitting $\mathrm{PO}_{4}$ adsorption data to $\mathrm{Fh}^{37}$

In the model, the proton affinity of both singly and triply coordinated groups has been set equal to the value of the point of zero charge (PZC) of Fh, according to 


$$
\begin{aligned}
& \equiv \mathrm{FeOH}^{-0.5}+\mathrm{H}^{+} \Leftrightarrow \equiv \mathrm{FeOH}_{2}{ }^{+0.5} \quad \log K_{\mathrm{H}}=\mathrm{PZC}=8.1 \\
& \equiv \mathrm{Fe}_{3} \mathrm{O}^{-0.5}+\mathrm{H}^{+} \Leftrightarrow \equiv \mathrm{Fe}_{3} \mathrm{OH}^{+0.5} \quad \log K_{\mathrm{H}}=\mathrm{PZC}=8.1
\end{aligned}
$$

The above surface groups may also react with the background electrolyte ions (i.e., $\mathrm{Na}^{+}, \mathrm{NO}_{3}^{-}$) forming ion pairs. For reasons of consistency, we will rely on the set of adsorption parameters recently published by Hiemstra and Zhao ${ }^{37}$ to describe the $\mathrm{PO}_{4}$ adsorption to Fh.

3.3.2. Carbonate Surface Complexes. Structural information about surface complexes obtained with in situ spectroscopy studies is useful to formulate, within the CD model approach, a set of reactions that realistically reflect the molecular picture of the adsorption mechanisms. For $\mathrm{CO}_{3}$, the surface speciation at the mineral-solution interface of metal-(hydr)oxides has been analyzed in several in situ spectroscopy studies.

Attenuated total reflectance-Fournier transformed infrared (ATR-FTIR) spectra have been interpreted previously as evidence for the dominant formation of inner-sphere monodentate $\mathrm{CO}_{3}$ complexes at the surfaces of goethite. ${ }^{51-53}$ The basis of this interpretation was the extent of peak splitting of the $\nu_{3}$ band $\left(\Delta \nu_{3}\right)$ of the $\mathrm{O}-\mathrm{C}-\mathrm{O}$ asymmetric stretching frequency, taking as a reference the $\Delta \nu_{3}$ value $\left(80-137 \mathrm{~cm}^{-1}\right)$ for the formation of inner-sphere monodentate $\mathrm{Co}$ (III)carbonato complexes in solution. ${ }^{54} \mathrm{~A}$ critical evaluation by Hiemstra et al., 55 combined with interpreting the charge distribution of the $\mathrm{CO}_{3}$ surface species with SCM, suggested the dominant formation of inner-sphere bidentate complexes of $\mathrm{CO}_{3}$ adsorbed to goethite. Bargar et al. ${ }^{56}$ characterized the adsorption of $\mathrm{CO}_{3}$ onto the hematite surface at various values of $\mathrm{pH}$ and ionic strength with ATR-FTIR spectroscopy and vibrational frequency calculations. The formation of an innersphere bidentate complex dominated the adsorption of $\mathrm{CO}_{3}$ to hematite, especially at a high background electrolyte concentration (i.e., $0.1 \mathrm{M} \mathrm{NaCl}$ ), whereas outer-sphere complexes may be relevant at a low $\mathrm{pH}$ and a low ionic strength. Kubicki et al. ${ }^{57}$ applied MO/DFT calculations on molecular clusters to model the IR vibrational frequencies of the surface complex structures for a series of oxyanions (i.e., $\left.\mathrm{CO}_{3}{ }^{2-}, \mathrm{PO}_{4}{ }^{3-}, \mathrm{SO}_{4}{ }^{2-}, \mathrm{AsO}_{4}{ }^{3-}\right)$. A good agreement was found between the $\mathrm{MO} / \mathrm{DFT}$ derived frequencies of a hydrated $\mathrm{CO}_{3}$ bidentate complex and the experimental frequencies reported by Bargar et al. ${ }^{56}$

For Fh, recent evidence obtained with in situ ATR-FTIR spectroscopy and DFT calculations also suggests the formation of inner-sphere bidentate complex as one of the main adsorption mechanisms for $\mathrm{CO}_{3}$ under atmospheric moisture conditions. ${ }^{17}$ Therefore, we will first consider in our modeling the formation of a binuclear bidentate carbonate complex (BC) with ligand exchange according to

$$
\begin{aligned}
2 & \equiv \mathrm{FeOH}(\mathrm{b})^{-0.5}+2 \mathrm{H}^{+}(\mathrm{aq})+\mathrm{CO}_{3}{ }^{2-}(\mathrm{aq}) \Leftrightarrow \\
& \equiv(\mathrm{FeO})_{2}{ }^{-1+\Delta z_{0}} \mathrm{CO}^{\Delta z_{1}}+2 \mathrm{H}_{2} \mathrm{O}(\mathrm{l}) \quad \log K_{\mathrm{BC}}
\end{aligned}
$$

in which $\Delta z_{0}$ and $\Delta z_{1}$ are the charge attributed to the surface and inner Stern plane by the adsorbed ions $\left(\Delta z_{0}+\Delta z_{1}=0\right)$.

Solely considering this $\mathrm{BC}$ complex in the modeling provides a good description of the experimental $\mathrm{PO}_{4}$ adsorption data for the series with $\mathrm{CO}_{3[\mathrm{~T}]}$ levels below 0.03 $M$. However, the quality of fitting the entire experimental data set was rather poor $\left(R^{2}=0.85, n=146\right)$. The $\mathrm{pH}$-dependency of the $\mathrm{PO}_{4}$ adsorption to $\mathrm{Fh}$ was underestimated at the higher values of $\mathrm{CO}_{3[\mathrm{~T}]}$, especially in the systems with the largest amount of added $\mathrm{PO}_{4}$ (i.e., 1.07 and $1.48 \mu \mathrm{mol} \mathrm{m} \mathrm{m}^{-2}$ ). Additionally, the effect of ionic strength on the $\mathrm{PO}_{4}-\mathrm{CO}_{3}$ competition was not well described.

In solution, $\mathrm{Na}^{+}$and $\mathrm{CO}_{3}{ }^{2-}$ ions may interact forming relatively weak, yet important, ion pairs. ${ }^{58,59} \mathrm{~A}$ similar interaction may occur at solid-solution interfaces. For a subset of data $(n=58)$, comprising only the adsorption series with $\mathrm{CO}_{3[\mathrm{~T}]}$ of 0.03 and $0.1 \mathrm{M}$ at three ionic strength levels ( $I$ $=0.05,0.1$, or $0.5 \mathrm{M})$, good description $\left(R^{2}=0.97\right)$ was found if ternary complex was included. The formation of a binuclear bidentate complex of $\mathrm{CO}_{3}$ interacting with a $\mathrm{Na}^{+}$ion $(\mathrm{BCNa})$ has been suggested previously for goethite $e^{29,51}$ and can be formulated as

$$
\begin{aligned}
2 & \equiv \mathrm{FeOH}(\mathrm{b})^{-0.5}+2 \mathrm{H}^{+}(\mathrm{aq})+\mathrm{CO}_{3}{ }^{2-}(\mathrm{aq})+\mathrm{Na}^{+}(\mathrm{aq}) \Leftrightarrow \\
& \equiv(\mathrm{FeO})_{2}{ }^{-1+\Delta z_{0}} \mathrm{CO} \cdots \mathrm{Na}^{+1+\Delta z_{1}}+2 \mathrm{H}_{2} \mathrm{O}(\mathrm{l}) \quad \log K_{\mathrm{BCNa}}
\end{aligned}
$$

Modeling the results of our $\mathrm{CO}_{3}-\mathrm{PO}_{4}$ competition experiments suggests an attribution of the full $\mathrm{Na}^{+}$charge to the 1-plane of the Stern layer (section 3.3.3). It does not necessarily imply that $\mathrm{Na}^{+}$forms an inner-sphere complex with the outer O-ligand of the adsorbed $\mathrm{CO}_{3}$. According to Bargar et al., ${ }^{56}$ a mechanism of $\mathrm{NaCO}_{3}$ inner-sphere complexation is less likely, based on $\mathrm{MO} / \mathrm{DFT}$ calculations comparing the experimental and calculated vibrational frequencies of $\mathrm{CO}_{3}$ adsorbed to hematite. If the $\mathrm{Na}^{+}$ion of our resolved $\mathrm{BCNa}$ complex binds as a $\mathrm{Na} \cdots \mathrm{CO}_{3}$ ion pair, the $\mathrm{Na}^{+}$ion may search for the interfacial location that allows the strongest electrostatic attraction, which will be the 1-plane as the electric potential of the inner Stern plane is most negative in our $\mathrm{PO}_{4}-\mathrm{CO}_{3}$ systems.

By using two $\mathrm{CO}_{3}$ inner-sphere complexes, a substantial part of our experimental data set can be well described. However, the adsorption of $\mathrm{PO}_{4}$ to $\mathrm{Fh}$ is slightly overpredicted by the model in our systems with the highest $\mathrm{CO}_{3[\mathrm{~T}]}$ levels $(0.2$ and $0.5 \mathrm{M})$; that is, the competitive effect of $\mathrm{CO}_{3}$ is still insufficiently predicted by the model $\left(\mathrm{R}^{2}=0.90, n=146\right)$. It is possible that an additional $\mathrm{CO}_{3}$ surface complex contributes to the $\mathrm{CO}_{3}-\mathrm{PO}_{4}$ interaction. To explore the possibilities, we have defined additionally the formation of a monodentate carbonate (MC) complex according to

$$
\begin{aligned}
\equiv & \mathrm{FeOH}^{-0.5}+\mathrm{H}^{+}(\mathrm{aq})+\mathrm{CO}_{3}{ }^{2-}(\mathrm{aq}) \Leftrightarrow \\
& \equiv \mathrm{FeO}^{-0.5+\Delta z_{0}} \mathrm{CO}_{2}{ }^{\Delta z_{1}}+1 \mathrm{H}_{2} \mathrm{O}(\mathrm{l}) \quad \log K_{\mathrm{MC}}
\end{aligned}
$$

Note that the MC complex can be formed by reacting with both types of $\equiv \mathrm{FeOH}^{-1 / 2}$ groups $\left(\left(\equiv \mathrm{FeOH}(\mathrm{a})^{-1 / 2}\right.\right.$ as well as $\left.\equiv \mathrm{FeOH}(\mathrm{b})^{-1 / 2}\right)$. For the surface complex in eq 8 , we searched for the charge distribution by free fitting of the CD coefficients, resulting in $\Delta z_{0}=0.26 \pm 0.08$ and $\Delta z_{1}=-1.26 \pm 0.08$ v.u. The obtained charge distribution shows that about $2 / 3$ of the charge of the divalent $\mathrm{CO}_{3}{ }^{2-}$ ion is present at the Stern plane and about $1 / 3$ is at the surface. According to the Pauling bond valence concept, this can be interpreted as the formation of a monodentate inner-sphere complex having one O-ligand common with the $\mathrm{Fe}$ in the surface while both other Oligands are outside the surface. The values for the $C D$ coefficients found by fitting are in good agreement with the ones found by optimizing the geometry of that complex with 
Table 1. Table Defining the Surface Species, CD Values, and $\log \mathrm{K}$ for the Adsorption Reactions of $\mathrm{CO}_{3}$ and $\mathrm{PO}_{4}$ to Ferrihydrite $^{a}$

\begin{tabular}{|c|c|c|c|c|c|c|c|c|c|c|c|c|}
\hline Surface species & ID $^{b}$ & $\equiv \mathrm{FeOH}(\mathrm{a})^{-0.5_{c}}$ & $\equiv \mathrm{FeOH}(\mathrm{b})^{-0.5_{c}}$ & $\equiv \mathrm{Fe} 3 \mathrm{O}^{-0.5}$ & $\Delta \mathrm{z}_{0}$ & $\Delta \mathrm{z}_{1}$ & $\Delta z_{2}$ & $\mathbf{H}^{+}$ & $\mathrm{CO}_{3}{ }^{2-}$ & $\mathrm{Na}^{+}$ & $\mathrm{PO}_{4}{ }^{3-}$ & $\log K$ \\
\hline$(\equiv \mathrm{FeO})_{2} \mathrm{CO}(\mathrm{b})$ & $\mathrm{BC}$ & 0 & 2 & 0 & 0.66 & -0.66 & 0 & 2 & 1 & 0 & 0 & $21.73 \pm 0.09^{d}$ \\
\hline$(\equiv \mathrm{FeO})_{2} \mathrm{CO} \cdots \mathrm{Na}(\mathrm{b})$ & $\mathrm{BCNa}$ & 0 & 2 & 0 & 0.65 & 0.35 & 0 & 2 & 1 & 1 & 0 & $22.38 \pm 0.09^{d}$ \\
\hline$\equiv \mathrm{FeOCO}_{2}(\mathrm{a})$ & MC & 1 & 0 & 0 & 0.34 & -1.34 & 0 & 1 & 1 & 0 & 0 & $11.60 \pm 0.01^{d}$ \\
\hline$\equiv \mathrm{FeOCO}_{2}(\mathrm{~b})$ & MC & 0 & 1 & 0 & 0.34 & -1.34 & 0 & 1 & 1 & 0 & 0 & $11.60 \pm 0.01^{d}$ \\
\hline$(\equiv \mathrm{FeO})_{2} \mathrm{PO}_{2}(\mathrm{~b})$ & $\mathrm{BP}$ & 0 & 2 & 0 & 0.46 & -1.46 & 0 & 2 & 0 & 0 & 1 & $28.31 \pm 0.04^{e}$ \\
\hline$(\equiv \mathrm{FeO})_{2} \mathrm{POOH}(\mathrm{b})$ & $\mathrm{BPH}$ & 0 & 2 & 0 & 0.65 & -0.65 & 0 & 3 & 0 & 0 & 1 & $33.52 \pm 0.13^{e}$ \\
\hline$\equiv \mathrm{FeOPO}_{2} \mathrm{OH}(\mathrm{a})$ & $\mathrm{MPH}$ & 1 & 0 & 0 & 0.28 & -1.28 & 0 & 2 & 0 & 0 & 1 & $26.36 \pm 0.20^{e}$ \\
\hline$\equiv \mathrm{FeOPO}_{2} \mathrm{OH}(\mathrm{b})$ & $\mathrm{MPH}$ & 0 & 1 & 0 & 0.28 & -1.28 & 0 & 2 & 0 & 0 & 1 & $26.36 \pm 0.20^{e}$ \\
\hline$\equiv \mathrm{FeOPO}(\mathrm{OH})_{2}(\mathrm{a})$ & MPH2 & 1 & 0 & 0 & 0.33 & -0.33 & 0 & 3 & 0 & 0 & 1 & $29.84 \pm 0.23^{e}$ \\
\hline$\equiv \mathrm{FeOPO}(\mathrm{OH})_{2}(\mathrm{~b})$ & $\mathrm{MPH} 2$ & $\begin{array}{l}0 \\
\rho A N_{s 1}^{f}\end{array}$ & $\begin{array}{l}1 \\
\rho A N_{\mathrm{s} 2}^{f}\end{array}$ & $\begin{array}{l}0 \\
\rho A N_{\mathrm{s} 3}^{f}\end{array}$ & $\begin{array}{l}0.33 \\
\Sigma_{1}^{f}\end{array}$ & $\begin{array}{l}-0.33 \\
\Sigma_{2}^{f}\end{array}$ & $\begin{array}{l}0 \\
\sum_{3}^{f}\end{array}$ & $\begin{array}{l}3 \\
\mathrm{H}_{\text {,tot }}\end{array}$ & $\begin{array}{l}0 \\
\mathrm{CO}_{3, \text { tot }}\end{array}$ & $\begin{array}{l}0 \\
\mathrm{Na}_{\text {,tot }}\end{array}$ & $\begin{array}{l}1 \\
\mathrm{PO}_{4, \text { tot }}\end{array}$ & $29.84 \pm 0.23^{e}$ \\
\hline
\end{tabular}

${ }^{a}$ The $\log K$ values for the $\mathrm{CO}_{3}$ surfaces species were found by fitting the experimental results of the binary adsorption systems $\mathrm{CO}_{3}-\mathrm{PO}_{4}(n=146)$. The surface site densities are from Hiemstra and $\mathrm{Zhao}^{37}$ with $\equiv \mathrm{FeOH}(\mathrm{a})=3 \mathrm{~nm}^{-2}$, $\equiv \mathrm{FeOH}(\mathrm{b})=2.8 \mathrm{~nm}^{-2}$, and $\equiv \mathrm{Fe}_{3} \mathrm{O}=1.4 \mathrm{~nm}^{-2}$. The capacitance values for the extended Stern layer are $\mathrm{C}_{1}=1.15 \mathrm{~F} \mathrm{~m}^{-2}$ and $\mathrm{C}_{2}=0.9 \mathrm{~F} \mathrm{~m}^{-2} .{ }^{b} \mathrm{BC}=$ Bidentate $\mathrm{CO}_{3}$ inner-sphere; $\mathrm{BCNa}=\mathrm{Bidentate}$ $\mathrm{CO}_{3}$ inner-sphere with $\mathrm{Na} ; \mathrm{MC}=$ Monodentate $\mathrm{CO}_{3}$ inner-sphere, $\mathrm{BP}=$ Bidentate $\mathrm{PO}_{4}$ inner-sphere; $\mathrm{BPH}=\mathrm{Bidentate} \mathrm{PO}_{4}$ inner-sphere protonated; $\mathrm{MPH}=$ Monodentate $\mathrm{PO}_{4}$ inner-sphere protonated; $\mathrm{MPH}_{2}=$ Monodentate $\mathrm{PO}_{4}$ inner-sphere doubly protonated. ${ }^{c} \equiv \mathrm{FeOH}(\mathrm{a})^{-0.5}$ forms only monodentate complexes with $\mathrm{PO}_{4}$ and $\mathrm{CO}_{3}$, whereas $\equiv \mathrm{FeOH}(\mathrm{b})^{-0.5}$ can form mono- and bidentate complexes, according to the ion adsorption model for Fh from Hiemstra and Zhao. ${ }^{37} d^{3} \log K($ mean \pm SD) are the average of the values obtained using four different fitting scales

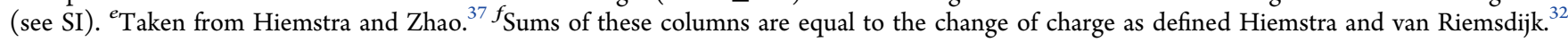

Table 2. Charge Distribution Values $\left(n_{0}, n_{1}\right)$ of Relevant $\mathrm{CO}_{3}{ }^{2-}$ Surface Complexes Derived from the MO/DFT Optimized Geometries, Applying the Brown Bond Valence Concept ${ }^{a}$

\begin{tabular}{|c|c|c|c|c|c|c|}
\hline Surface species & ID $^{b}$ & $\mathbf{n}_{0}{ }^{c}$ & $\mathbf{n}_{1}^{c}$ & $\Delta \mathrm{z}_{0}$ & $\Delta \mathrm{z}_{1}$ & $\Delta \mathbf{z}_{2}$ \\
\hline$(\equiv \mathrm{FeO})_{2} \mathrm{CO}(\mathrm{b})$ & $\mathrm{BC}$ & $-1.40 \pm 0.01$ & $-0.60 \pm 0.01$ & 0.66 & -0.66 & 0 \\
\hline$(\equiv \mathrm{FeO})_{2} \mathrm{CO} \cdots \mathrm{Na}(\mathrm{b})$ & $\mathrm{BCNa}$ & $-1.42 \pm 0.02$ & $-0.58 \pm 0.02$ & 0.65 & 0.35 & 0 \\
\hline$\equiv \mathrm{FeOCO}_{2}(\mathrm{a})$ & $\mathrm{MC}$ & $-0.70 \pm 0.01$ & $-1.30 \pm 0.01$ & 0.34 & -1.34 & 0 \\
\hline$\equiv \mathrm{FeOCO}_{2}(\mathrm{~b})$ & MC & $-0.70 \pm 0.01$ & $-1.30 \pm 0.01$ & 0.34 & -1.34 & 0 \\
\hline
\end{tabular}

${ }^{a_{T}}$ The CD coefficients $\left(\Delta z_{0}, \Delta z_{1}\right)$ include the change of charge due to the reaction with protons $\left(n_{\mathrm{H} 0}, n_{\mathrm{H} 1}\right)$ and a correction for the interfacial water dipole orientation. ${ }^{b} \mathrm{BC}=$ Bidentate $\mathrm{CO}_{3}$ inner-sphere; $\mathrm{BCNa}=$ Bidentate $\mathrm{CO}_{3}$ inner-sphere with Na; $\mathrm{MC}=$ Monodentate $\mathrm{CO}_{3}$ inner-sphere. ${ }^{c}$ Mean values $( \pm \mathrm{SD})$ obtained from six different QC models (BP86, B3LYP, EDF1, EDF2, BLYP, $\omega$ P97X-D).

$\mathrm{MO} / \mathrm{DFT}$, i.e. $\Delta z_{0}=0.34, \Delta z_{1}=-1.34$ v.u., which will be discussed in section 3.3.3.

The $\log K$ value for the above set of reactions is presented in Table 1 and corresponds to the average values found by evaluating the data at four different scales (i.e., \% $\mathrm{PO}_{4}$ adsorbed, $\mathrm{PO}_{4}$ solution concentration, log $\mathrm{PO}_{4}$ solution concentration, and $\mu \mathrm{mol} \mathrm{PO}_{4}$ adsorbed $\mathrm{m}^{-2}$ ). In Table S-4 of the Supporting Information, the $\log K$ values fitted for each evaluation scale are given. The use of the parameter set presented in Table 1 and Table S-4 resulted in a good description of the entire data set $\left(\mathrm{R}^{2}>0.94\right.$, for all different scales).

Presently, we cannot entirely rule out for $\mathrm{CO}_{3}$ the formation of an outer-sphere complex at the surfaces of Fh. In our modeling, considering the formation of outer-sphere complexes instead of the monodentate inner-sphere yields a similar quality of fitting (Appendix 4 in the SI) and describes the adsorption of $\mathrm{CO}_{3}$ to $\mathrm{Fh}$ in monocomponent systems well. Spectroscopic information does suggest the formation of $\mathrm{CO}_{3}$ outer-sphere complexes at the interfaces of $\mathrm{Fe}$-(hydr)oxides. However, these complexes were particularly found at low $\mathrm{pH}$ and a low to very low ionic strength. ${ }^{56}$ For other oxyanions $\left(\mathrm{SeO}_{4}{ }^{2-}, \mathrm{CrO}_{4}{ }^{2-}, \mathrm{SO}_{4}{ }^{2-}\right)$, recent spectroscopy suggests a combination of inner- and outer-sphere complexes as mechanism to explain the adsorption to Fe-(hydr)oxides. ${ }^{47,60,61}$ However, all that presently matters is that according to the $\mathrm{CD}$ model any additional complex (either outer-sphere or inner-sphere complex) is contributing little in our systems. Binuclear bidentate complex formation of $\mathrm{CO}_{3}$ is found to be dominant, as shown later in detail.

It is important to note that the introduction of a $\mathrm{HCO}_{3}{ }^{-}$ surface complex did not improve the description of our data, yet $\mathrm{HCO}_{3}{ }^{-}$dominates the solution speciation of $\mathrm{CO}_{3}$ over most of our experimental $\mathrm{pH}$ range. This agrees with the observation that surface complexes with $\mathrm{CO}_{3}{ }^{2-}$ complexes dominate the surface speciation under atmospheric moisture conditions, whereas $\mathrm{HCO}_{3}{ }^{-}$complexes are only preferentially formed upon dehydration. ${ }^{17,62,63}$ In addition, our optimization of the geometry of a monodentate $\mathrm{HCO}_{3}{ }^{-}$complex with $\mathrm{MO} /$ DFT shows that the proton of the adsorbed $\mathrm{HCO}_{3}$ spontaneously shifts toward an adjacent $\equiv \mathrm{FeOH}^{-1 / 2}$ group if present in an $\mathrm{O}-\mathrm{H}^{\cdots} \mathrm{O}$ bond. This spontaneous shift leads formally to the formation of a $\equiv \mathrm{FeOH}_{2}{ }^{+1 / 2}$ group and deprotonation of monodentate inner-sphere complex.

3.3.3. Charge Distribution Coefficients. In the CD model, the ionic charge of an inner-sphere complex is distributed over two different electrostatic planes at the interface. This interfacial charge distribution is accounted for by means of the CD coefficients $\left(\Delta z_{0}, \Delta z_{1}\right)$. In the original approach, ${ }^{32}$ the $\mathrm{CD}$ coefficients were estimated by assuming symmetrical distribution of the charge of the central ion over its ligands (Pauling bond valence). However, differences in the bonds lengths between the central ion and the coordinating ligands will lead to an asymmetrical charge distribution. Bond length differences can be interpreted with the semiempirical Brown 

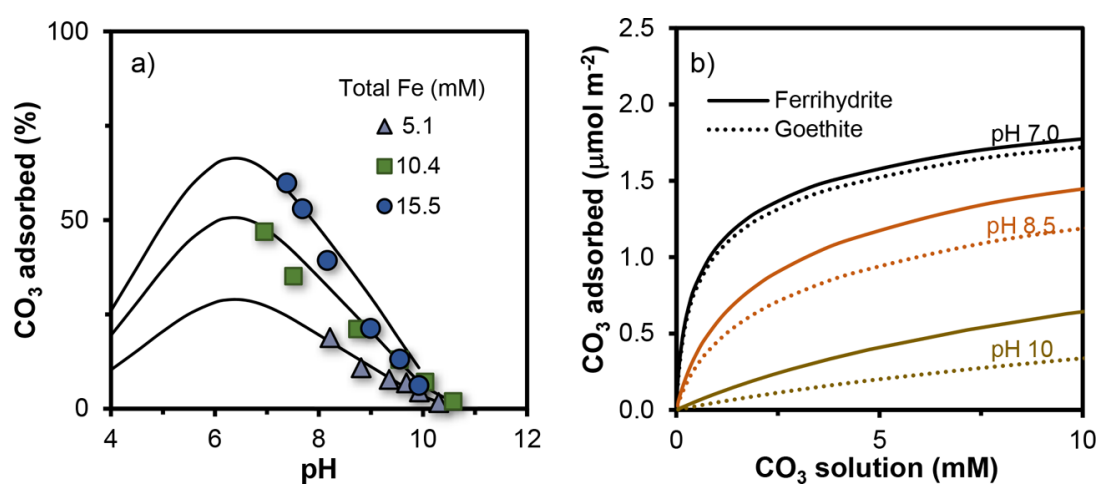

Figure 4. (a) Adsorption edges of $\mathrm{CO}_{3}$ in single-ion systems with ferrihydrite at a constant ionic strength $\left(I=0.1 \mathrm{M} \mathrm{NaNO}_{3}\right)$. The black lines are $\mathrm{CD}$ model predictions using the parameter set of Table 1, that has been derived based on only interpreting competitive $\mathrm{PO}_{4}$ adsorption data in carbonate systems. The adsorption edges are for systems with $\mathrm{CO}_{3[\mathrm{~T}]}=1 \mathrm{mM}$ and three $\mathrm{Fe}_{[\mathrm{T}]}(5.1,10.4$, and $15.5 \mathrm{mM})$. The specific surface area of ferrihydrite was $A=625 \mathrm{~m}^{2} \mathrm{~g}^{-1}$ at a corresponding molar mass of $M_{\text {nano }}=95.14 \mathrm{~g} \mathrm{~mol}^{-1} \mathrm{Fe}$. (b) Modeled adsorption isotherms of $\mathrm{CO}_{3}$ to ferrihydrite (full lines) and goethite (dotted lines) at a constant ionic strength $(I=0.10 \mathrm{M})$ and three $\mathrm{pH}$ values: 7.0, 8.5, and 10.0. Model parameters for ferrihydrite are from Table 1 , whereas for goethite they are taken from Rahnemaie et al. ${ }^{29}$

valence concept, ${ }^{34,35}$ which relates bond length $(R)$ to a bond valence $(s)$.

In our approach, we have used MO/DFT calculations to optimize the geometry of a series of different $\mathrm{CO}_{3}-\mathrm{Fe}$ complexes and derive subsequently the values of the $\mathrm{CD}$ coefficients. This approach has the advantage of restricting the number of adjustable parameters per surface species to one (i.e., $\log K)$. The optimized geometries of the relevant $\mathrm{CO}_{3}$ surface complexes used in the final modeling are presented in the graph of the table of contents (TOC).

In Table 2 , the ionic charge distribution values $\left(n_{0}, n_{1}\right)$ are presented for the different $\mathrm{CO}_{3}$ surface species considered in our modeling (section 3.3.2). Detailed information about the bond length distances and the application of the Brown bond concept is given in Appendix 9 of the SI. The final CD coefficients $\left(\Delta z_{0}, \Delta z_{1}\right)$ include the change of charge that results from the protons involved $\left(n_{\mathrm{H} 0}, n_{\mathrm{H} 1}\right)$ in the formation reactions (eqs 6-8). In addition, there is a correction term $\left( \pm \varphi_{\mathrm{m}} \Lambda_{0}\right)$ for the interfacial water dipole orientation. The factor $\varphi_{m}$ is a constant $(0.17 \pm 0.02),{ }^{42}$ and $\Lambda_{0}$ is the change of charge relatively to that of the reference state from which the reaction is defined. Therefore, $\Lambda_{0}=n_{0}+n_{\mathrm{H} 0}+\Sigma n_{\text {ref }} \times z_{\text {ref }}$ in which $n_{\text {ref }}$ and $z_{\text {ref }}$ are the number and the charge of the reference surface groups involved, respectively. ${ }^{39}$

As follows from the $n_{0}$ and $n_{1}$ values presented in Table 2, there is some asymmetry in the distribution of the central $\mathrm{C}^{4+}$ charge over the different $-\mathrm{O}$ ligands of the $\mathrm{CO}_{3}$ surface complexes. Slightly more negative charge is attributed to the $\mathrm{Fe}-\mathrm{O}-\mathrm{C}$ bonds in comparison to the symmetrical charge distribution according to the Pauling bond valence concept. The interaction of the bidentate carbonate complex with a $\mathrm{Na}^{+}$ ion does not affect significantly the $n_{0}$ and $n_{1}$ values of the $\mathrm{O}$ ligands in this ternary complex, which implies that no significant transfer of charge occurs from the $\mathrm{Na}^{+}$to the $\mathrm{O}$ ligands of the bidentate complex. Free fitting of the $C D$ coefficients of the $\mathrm{BCNa}$ complex suggests a full attribution of the $\mathrm{Na}^{+}$charge to the 1-plane of the Stern layer. The $\Delta z_{1}$ value of the BCNa complex in Table 2 includes the charge of $\mathrm{Na}^{+}$.

The results presented in Table 2 are for complexes optimized using an uncharged $\left(\mathrm{H}_{2} \mathrm{O}\right)_{2} \mathrm{Fe}_{2}(\mathrm{OH})_{6}\left(\mathrm{OH}_{2}\right)_{2}$ template (A) that has also been used previously to derive the $\mathrm{CD}$ coefficients for the $\mathrm{PO}_{4}$ surface species. ${ }^{37,42}$ It has been shown that the charge of the template may influence the calculated CD coefficients; ${ }^{29}$ that is, the charge distribution may depend on the protonation/deprotonation of the overall moiety. ${ }^{5}$ Calculations performed with a positive charged template, $\left(\mathrm{H}_{2} \mathrm{O}\right)_{2} \mathrm{Fe}_{2}(\mathrm{OH})_{4}\left(\mathrm{OH}_{2}\right)_{4}$ (B) resulted in more transfer of negative charge $(-0.09$ v.u. $)$ to the common $\mathrm{O}$ ligands for the binuclear bidentate $\mathrm{CO}_{3}$ complexes in comparison with template A. Nevertheless, this variation was still lower in comparison with the uncertainty of the $C D$ coefficients $( \pm 0.25$ v.u.) found at free fitting of the $C D$ value using our experimental data. For the $\mathrm{CO}_{3}-\mathrm{PO}_{4}$ competition experiments, the same quality of the fitting was obtained using either template A or B as model. However, use of template A leads to a better prediction of the adsorption of $\mathrm{CO}_{3}$ in monocomponent systems.

3.4. Model Applications. 3.4.1. Carbonate Adsorption in Single-Ion Systems. The suitability of the above-derived CD model parameters for describing the adsorption of $\mathrm{CO}_{3}$ in single-ion systems with $\mathrm{Fh}$ will be evaluated here. Batch adsorption experiments were performed using three $\mathrm{Fe}_{[\mathrm{T}]}$ levels $(5.1,10.4$, and $15.5 \mathrm{mM})$ at a fixed initial $\mathrm{CO}_{3[\mathrm{~T}]}$ of 1 $\mathrm{mM}$ and a constant ionic strength of $0.10 \mathrm{M} \mathrm{NaNO}_{3}$. The $\mathrm{pH}$ of the systems varied from 6.9 to 10.5. As shown in Figure 4a, the adsorption of $\mathrm{CO}_{3}$ to $\mathrm{Fh}$ continuously decreases as the solution $\mathrm{pH}$ increases from 7 to 10 (symbols). The solid lines are the corresponding $C D$ model predictions for the adsorption of $\mathrm{CO}_{3}$ in these systems, using the parameter values of Table 1 . Interestingly, these parameters have been derived without any direct measurement of the $\mathrm{CO}_{3}$ adsorption. The excellent prediction obtained for the singleion systems shows that the $\mathrm{CD}$ model can be well parametrized for $\mathrm{CO}_{3}$ by only measuring the competitive effect of this anion on the adsorption of $\mathrm{PO}_{4}$ to $\mathrm{Fh}$. In addition, it is noted that the total concentration of $\mathrm{CO}_{3}$ is 4 to 500 times lower in the single-ion experiments than applied in the competition experiments. The good agreement between the experimental adsorption edges and the model predictions evidences the reliability of the $\mathrm{CD}$ model to describe the adsorption of $\mathrm{CO}_{3}$ over a broad range of conditions. This is highly relevant from an environmental point of view as $\mathrm{CO}_{3}$ is omnipresent in soils, sediments, rivers, groundwater, and marine systems at highly variable conditions. It will contribute to an improved modeling of the geochemical cycle of a range of compounds relevant from the environmental perspective. ${ }^{64-66}$ 

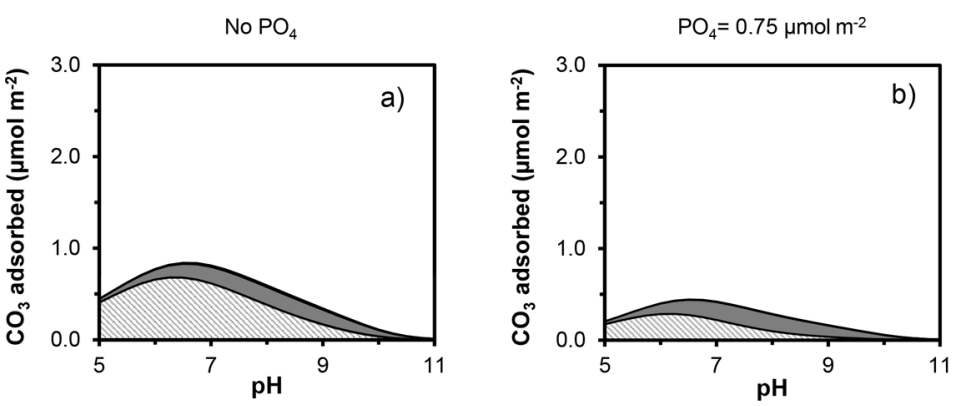

$\mathrm{CO}_{3}=0.001 \mathrm{M}$
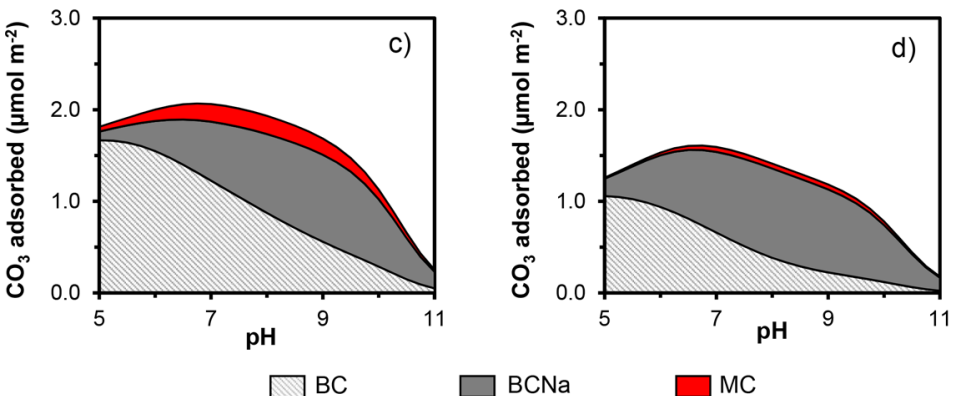

$\mathrm{CO}_{3}=0.03 \mathrm{M}$

Figure 5. Surface speciation of $\mathrm{CO}_{3}$ on ferrihydrite as a function of $\mathrm{pH}$ for single $\mathrm{CO}_{3}$ systems (left panels) and binary $\mathrm{CO}_{3}-\mathrm{PO}_{4}$ systems (right panels). The $\mathrm{CD}$ model calculations were performed with the $\mathrm{CO}_{3}$ and $\mathrm{PO}_{4}$ parameter set presented Table 1 . The upper panels (a and $\mathrm{b}$ ) are for systems with a $\mathrm{CO}_{3[\mathrm{~T}]}=0.001 \mathrm{M}$, whereas the lower panels $\left(\mathrm{c}\right.$ and $\mathrm{d}$ ) are for systems with $\mathrm{CO}_{3(\mathrm{~T})}=0.03 \mathrm{M}$. The ferrihydrite concentration was 0.5 $\mathrm{g} \mathrm{L}^{-1}$ with an assumed SSA of $670 \mathrm{~m}^{2} \mathrm{~g}^{-1}$. The ionic strength in all the systems was adjusted at $0.05 \mathrm{M}$ by adding $\mathrm{NaNO}_{3}$.

According to our model simulations (Figure 4a), the adsorption maximum of $\mathrm{CO}_{3}$ to $\mathrm{Fh}$ occurs around $\mathrm{pH} 6.5-$ 7.0. This maximum is nearly independent from the solid-tosolution ratio of the system. Above $\mathrm{pH} \sim 6.5$, the $\mathrm{CO}_{3}$ adsorption decreases at increase of $\mathrm{pH}$, while the opposite occurs below $\mathrm{pH} \sim 6.5$. This behavior has also been found for goethite by Villalobos and Leckie ${ }^{16}$ and can be predicted very well with the CD model. ${ }^{29}$ A similar $\mathrm{pH}$-dependency has also been found by Zachara et al. ${ }^{24}$ for single-ion systems with Fh. Even though measured for very low $\mathrm{CO}_{3}$ concentrations (i.e., $\mu \mathrm{M}$ levels), the $\mathrm{pH}$-dependency of this data set can also be predicted well with the present CD model (Table 1), as shown in Figure S-6 in the Supporting Information.

The characteristic pH-dependency of the $\mathrm{CO}_{3}$ adsorption with a maximum in the adsorption edge (Figure $4 \mathrm{a}$ ) is due to a change in solution speciation. The $\mathrm{pH}$-dependency of adsorption is a trade-off between proton binding to surface and solution species. According to the thermodynamic consistency principle, ${ }^{39,67,68}$ the change $(\partial)$ of the logarithm of the solution concentration with $\mathrm{pH}$ is

$$
\left(\frac{\partial \log C_{\mathrm{CO} 3(\mathrm{~T})}}{\partial \mathrm{pH}}\right)_{\Gamma_{\mathrm{CO} 3}}=\left(\chi_{\mathrm{H}}-n_{\mathrm{H}}\right)_{\mathrm{pH}}
$$

in which $\chi_{\mathrm{H}}$ is the molar ratio of the proton excess adsorption upon adsorption of $\mathrm{CO}_{3}$, known as proton coadsorption ratio, and $n_{\mathrm{H}}$ is the mean number of protons bound to dissolved $\mathrm{CO}_{3}$ species, both defined relatively to a chosen reference species. Calculations show that the proton coadsorption is about $\chi_{\mathrm{H}} \sim$ 1.5 at neutral $\mathrm{pH}$. Using $\mathrm{CO}_{3}{ }^{2-}(\mathrm{aq})$ as reference, $n_{\mathrm{H}}=+2$ when $\mathrm{H}_{2} \mathrm{CO}_{3}(\mathrm{aq})$ dominates the system at $\mathrm{pH}<\log K_{\mathrm{H} 2}=$ 6.35, and $\chi_{\mathrm{H}}-n_{\mathrm{H}}<0$, while $\chi_{\mathrm{H}}-n_{\mathrm{H}}>0$ for $n_{\mathrm{H}}=+1$ in a solution dominated by $\mathrm{HCO}_{3}^{-}(\mathrm{aq})(\mathrm{pH}>6.35)$. The change of $n_{\mathrm{H}}$ leads to the remarkable switch in $\mathrm{pH}$-dependency shown in Figure 4 a. At $\mathrm{pH} \sim \log K_{\mathrm{H} 2}, n_{\mathrm{H}}=1.5$ and $\chi_{\mathrm{H}}-n_{\mathrm{H}} \sim 0$. This implies that at this condition, there will be no $\mathrm{pH}$-dependency of the $\mathrm{CO}_{3}$ adsorption. This coincides with the top of the curves in Figure 4a. The above thermodynamic consistency principle can also be applied to the adsorption of other ions, including the adsorption of $\mathrm{Si}$ to $\mathrm{Fh}$, as discussed recently in detail. $^{5}$

In Figure 4b, the modeled adsorption isotherms of $\mathrm{CO}_{3}$ to Fh (full lines) are presented for systems at $\mathrm{pH} 7.0,8.5$, and 10.0. For comparison, the corresponding adsorption isotherms to goethite $(\alpha-\mathrm{FeOOH})$ have also been modeled (dotted lines), using the $\mathrm{CD}$ model parameters from Rahnemaie et al. ${ }^{29}$ At $\mathrm{pH} 7.0$, the adsorption of $\mathrm{CO}_{3}$ to both $\mathrm{Fe}$-(hydr)oxide minerals is similar over the entire range of solution concentrations. As the $\mathrm{pH}$ increases, more $\mathrm{CO}_{3}$ is adsorbed to $\mathrm{Fh}$ than to goethite, under similar solution conditions. This difference is more significant at increased $\mathrm{CO}_{3}$ loadings, and it can be related to differences in the surface speciation of $\mathrm{CO}_{3}$ of both minerals. Particularly important is the enhanced formation of the $\mathrm{BCNa}$ complex in the $\mathrm{Fh}$ systems. Formulating the formation of the $\mathrm{BCNa}$ complex according to

$$
\begin{aligned}
& \equiv(\mathrm{FeO})_{2}{ }^{-1+\Delta z_{0}} \mathrm{CO}^{\Delta z_{1}}+\mathrm{Na}^{+}(\mathrm{aq}) \\
& \Leftrightarrow \equiv(\mathrm{FeO})_{2}{ }^{-1+\Delta z_{0}} \mathrm{CO} \cdots \mathrm{Na}^{+1+\Delta z_{1}}
\end{aligned}
$$

the corresponding equilibrium constant of the reaction is $\log K$ +0.65 for Fh and $\log K+0.02$ for goethite. The difference shows that for a given solution condition, the formation of the $\mathrm{BCNa}$ is more favored at the surfaces of Fh. The $\mathrm{pH}$ and concentration dependence of the $\mathrm{CO}_{3}$ surface speciation in $\mathrm{Fh}$ is presented in Figure 5 and Figure S-5 (see SI), respectively.

3.4.2. Carbonate Surface Speciation. In this section, we evaluate the effect of $\mathrm{pH}, \mathrm{CO}_{3(\mathrm{~T})}$, and the presence of $\mathrm{PO}_{4}$ on the surface speciation of adsorbed $\mathrm{CO}_{3}$ (Figure 5). It is observed that the distribution of the adsorbed $\mathrm{CO}_{3}$ over the different surface species is strongly affected by the $\mathrm{pH}$ of the solution. The $\mathrm{BC}$ complex is the dominant $\mathrm{CO}_{3}$ surface species in the low $\mathrm{pH}$ range (Figure $5 \mathrm{a}-\mathrm{d}$ ). As the $\mathrm{pH}$ increases, the 

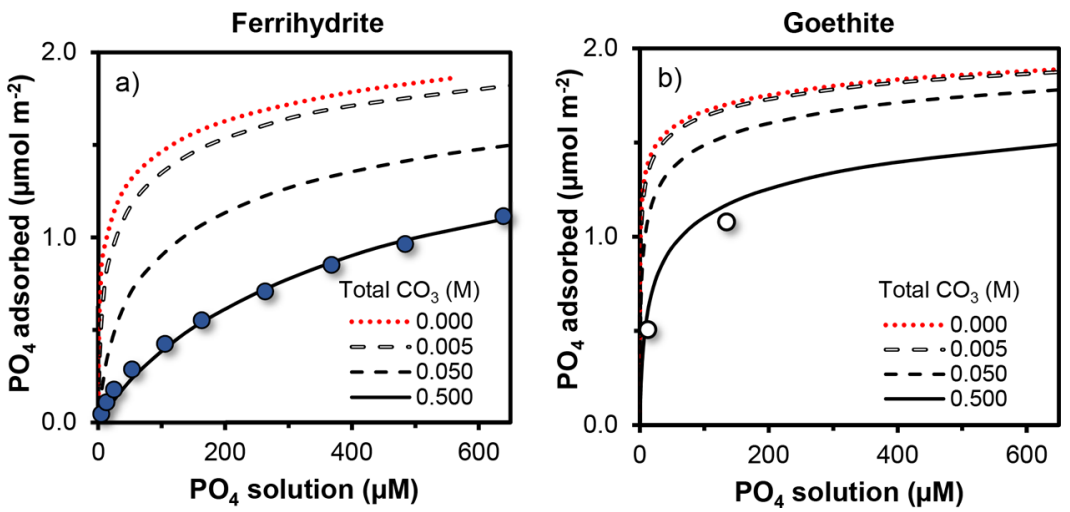

Figure 6. Panel a: Adsorption isotherm of $\mathrm{PO}_{4}$ to ferrihydrite in $0.5 \mathrm{M} \mathrm{NaHCO}_{3}$ at $\mathrm{pH} 8.70 \pm 0.01$. The specific surface area of the ferrihydrite was $A=735 \mathrm{~m}^{2} \mathrm{~g}^{-1}$ with a respective molar mass of $M_{\text {nano }}=97.98 \mathrm{~g} \mathrm{~mol}^{-1} \mathrm{Fe}$. The total reactive area was $375 \mathrm{~m}^{2} \mathrm{~L}^{-1}$. The symbols are experimental data and the (full) line is the model prediction. For comparison, the calculated $\mathrm{PO}_{4}$ adsorption isotherms for systems with 0 (red dotted line), 0.005 (open-dashed line), and $0.05 \mathrm{M}$ (dashed line) $\mathrm{CO}_{3[\mathrm{~T}]}$ have also been included in the graph. The ionic strength was fixed at $0.5 \mathrm{M}$ by adding $\mathrm{NaNO}_{3}$ when required. CD model calculations were performed with the parameters presented in Table 1. Panel b: Modeled adsorption isotherms of $\mathrm{PO}_{4}$ to goethite in the absence (red dotted line) and presence (black lines) of $\mathrm{CO}_{3}$ for the same solution as used in panel a. Modeling parameters and $\mathrm{PO}_{4}$ adsorption data points were taken from Rahnemaie et al. ${ }^{29}$

relative contribution of the $\mathrm{BCNa}$ complex to the total $\mathrm{CO}_{3}$ adsorption gradually increases. The relative importance of the $\mathrm{BCNa}$ complex further increases at a high loading of $\mathrm{CO}_{3}$ and/ or $\mathrm{PO}_{4}$ (Figure $5 \mathrm{c}$ and $\mathrm{d}$ ), which can be understood from the increase of the negative value of the electrostatic potential in the inner Stern (1-) plane. This leads for the $\mathrm{Na}^{+}$ions to a stronger attraction and formation of the ternary surface species.

Figure 5 also depicts that the formation of the $\mathrm{MC}$ complex is almost negligible at a low $\mathrm{CO}_{3[\mathrm{~T}]}$ level (Figures $5 \mathrm{a}$ and $\mathrm{b}$ vs $\mathrm{c}$ and $\mathrm{d}$ ). This fits with our modeling experience (section 3.3.2) that the incorporation of this $\mathrm{MC}$ species was only necessary to describe the results of the $\mathrm{CO}_{3}-\mathrm{PO}_{4}$ competition experiments at the high $\mathrm{CO}_{3[\mathrm{~T}]}$ levels. In addition, comparison of the single and binary ion systems (Figures $5 \mathrm{c}$ vs $\mathrm{d}$ ) shows that at the chosen $\mathrm{CO}_{3[\mathrm{~T}]}$ level, the formation of the $\mathrm{MC}$ complex is reduced when $\mathrm{PO}_{4}$ is present. This effect also follows from electrostatic considerations. As mentioned before, the specific adsorption of $\mathrm{PO}_{4}$ induces uncompensated negative charge that increases the negative electrostatic potential of the inner Stern or 1-plane (see Figure S-7 in the Supporting Information). Since MC complex introduces more negative charge in the 1-plane $\left(\Delta z_{1}=-1.34\right.$ v.u. $)$ than BC complexes $\left(\Delta z_{1}=-0.66\right.$ v.u. $)$, the formation of the former surface complex is most suppressed in the presence of $\mathrm{PO}_{4}$.

3.4.3. $\mathrm{PO}_{4}$ Extraction with Carbonate Solution. The competitive interaction $\mathrm{CO}_{3}-\mathrm{PO}_{4}$ has been traditionally used in soil chemical analysis to evaluate the soil $\mathrm{PO}_{4}$ availability in natural and agricultural systems. ${ }^{69,70}$ More recently, this interaction has been applied to derive the effective reactive surface area (RSA) of soils. ${ }^{31}$ In the present study, we have measured the $\mathrm{PO}_{4}$ adsorption isotherm for $\mathrm{Fh}$ in $0.5 \mathrm{M} \mathrm{NaHCO}_{3}(\mathrm{pH}=8.70 \pm 0.01)$ over a range of equilibrium $\mathrm{PO}_{4}$ concentrations $(\sim 5-650 \mu \mathrm{M})$ that represents the conditions typically found when natural and fertilized field samples are extracted with $0.5 \mathrm{M} \mathrm{NaHCO}_{3} .{ }^{70}$ The lines in Figure $6 \mathrm{a}$ are predictions with the $\mathrm{CD}$ model, showing an accurate prediction of the $\mathrm{PO}_{4}$ adsorption density $\left(\mu \mathrm{mol} \mathrm{m}{ }^{-2}\right)$ for the systems in competition with $\mathrm{CO}_{3}$, using the set of adsorption parameters presented in Table 1.

As an example of the competitive effect of added $\mathrm{NaHCO}_{3}$ at a $\mathrm{pH}$ condition relevant in soil extractions, additional $\mathrm{PO}_{4}$ adsorption isotherms have been calculated for systems with an increasing $\mathrm{CO}_{3[\mathrm{~T}]}$ (dashed lines), as well as for systems with no $\mathrm{CO}_{3}$ addition (red dotted line). $\mathrm{CO}_{3}$ is a good competitor at high concentrations, removing a significant amount of adsorbed $\mathrm{PO}_{4}$ from the surfaces of $\mathrm{Fh}$. It diminishes the high affinity character (shape) of the $\mathrm{PO}_{4}$ adsorption isotherm (Figure 6a).

Figure $6 \mathrm{~b}$ shows the adsorption isotherms of $\mathrm{PO}_{4}$ for goethite $(\alpha-\mathrm{FeOOH})$ calculated with the $\mathrm{CD}$ model parameters derived by Rahnemaie et al. ${ }^{29}$ This latter material has been used to derive the RSA soil samples, while results suggest that the natural oxide fraction is dominated by nanoparticles (e.g., $\mathrm{Fh}){ }^{31}$ In the absence of $\mathrm{CO}_{3}$, the adsorption of $\mathrm{PO}_{4}$ is similar in both $\mathrm{Fe}$-(hydr)oxide materials. However, $\mathrm{CO}_{3}$ removes less $\mathrm{PO}_{4}$ from goethite than from $\mathrm{Fh}$ at the same solution conditions. The $\mathrm{PO}_{4}$ adsorption isotherm in goethite remains steeper. The results in Figure 6 agree with the model simulations presented previously in Figure $4 \mathrm{~b}$, which showed that at high $\mathrm{pH}, \mathrm{CO}_{3}$ has a higher adsorption affinity for $\mathrm{Fh}$ than for goethite. This results in a stronger competition with $\mathrm{PO}_{4}$ in the systems with $\mathrm{Fh}$.

With the collected information on Figure 6, one may assess the RSA $\left(\mathrm{m}^{2} \mathrm{~g}^{-1}\right.$ soil) based on the change $(\Delta)$ of the $\mathrm{PO}_{4}$ amount in solution and the change in surface loading $\Delta \Gamma_{\mathrm{PO}_{4}}$ $\left(\mathrm{mol} \mathrm{m}{ }^{-2}\right)$, according to

$$
\mathrm{RSA}=\frac{\Delta\left(c_{\mathrm{PO}_{4}} \times \mathrm{SSR}\right)}{\Delta \Gamma_{\mathrm{PO}_{4}}}
$$

in which $c_{\mathrm{PO}_{4}}$ is the experimental $\mathrm{PO}_{4}$ concentration $\left(\mathrm{mol} \mathrm{L}^{-1}\right)$ and SSR is the solution-to-soil ratio (in $\mathrm{L} \mathrm{kg}^{-1}$ ). The measured change in concentration $\Delta c_{\mathrm{PO} 4}\left(\mathrm{~mol} \mathrm{~L}^{-1}\right)$ is translated into a corresponding change in $\mathrm{PO}_{4}$ surface loading $\Delta \Gamma_{\mathrm{PO} 4}(\mu \mathrm{mol}$ $\mathrm{m}^{-2}$ ) calculated with the $\mathrm{CD}$ model.

As follows from Figure 6, the relation between $\Delta c_{\mathrm{PO} 4}$ and $\Delta \Gamma_{\mathrm{PO} 4}$ value is clearly determined by the slope of the adsorption isotherm and consequently depends on the type of $\mathrm{Fe}$-(hydr)oxide used as reference material. A steeper adsorption isotherm will lead to more buffering of the $\mathrm{PO}_{4}$ concentration, i.e. smaller $\Delta c_{\mathrm{PO} 4}$ at the same $\Delta \Gamma_{\mathrm{PO} 4}$, leading to a lower value for the calculated RSA. In $0.5 \mathrm{M} \mathrm{NaHCO}_{3}$, goethite has a $\mathrm{PO}_{4}$ adsorption isotherm that is relatively flat at 
a high $\mathrm{PO}_{4}$ concentration compared to $\mathrm{Fh}$. This implies that its use as reference oxide to calculate the reactive surface area of soils will lead to higher values than with the use of $\mathrm{Fh}$ as reference oxide. This illustrates that precise information about the adsorption isotherm of the natural oxide fraction is essential for a correct assessment of the effective RSA of soil samples. In a forthcoming contribution, we will evaluate the use of $\mathrm{Fh}$ as nanoparticulate proxy for the natural metal oxide fraction of soils by applying the information collected in the present study.

\section{CONCLUSIONS}

In the present study, we aim to quantify the interaction of $\mathrm{CO}_{3}$ with $\mathrm{Fh}$ by measuring its competitive effect on the adsorption of $\mathrm{PO}_{4}$ in closed systems. Our analysis starts by evaluating the effect of high $\mathrm{CO}_{3}$ concentrations on the solubility of Fh, since $\mathrm{Fe}(\mathrm{III})-\mathrm{CO}_{3}$ complexes may form while our freshly prepared $\mathrm{Fh}$ is relatively soluble. Three aqueous species $\mathrm{FeOH}$ $\mathrm{CO}_{3}{ }^{0}(\mathrm{aq}), \mathrm{Fe}\left(\mathrm{CO}_{3}\right)_{3}{ }^{3-}(\mathrm{aq})$, and $\mathrm{Fe}\left(\mathrm{CO}_{3}\right)_{2}(\mathrm{OH})_{2}{ }^{3-}(\mathrm{aq})$ are found to be relevant according to modeling literature ${ }^{38}$ and our own data. The latter species is most important in our closed systems, while both others are more relevant in open systems. At the chosen conditions in the adsorption experiments, only a very small fraction of $\mathrm{Fh}(<0.4 \%)$ was dissolved, enabling straightforward interpretation of the collected $\mathrm{CO}_{3}$ adsorption data.

$\mathrm{CO}_{3}$ competes with $\mathrm{PO}_{4}$ for the adsorption sites of the $\mathrm{Fh}$ surface. However, $\mathrm{PO}_{4}$ has a significantly larger affinity than $\mathrm{CO}_{3}$ for these binding sites, meaning that high $\mathrm{CO}_{3} / \mathrm{PO}_{4}$ concentration ratios are needed to remove $\mathrm{PO}_{4}$ efficiently from the surface of Fh. The competitive interaction $\mathrm{CO}_{3}-\mathrm{PO}_{4}$ in $\mathrm{Fh}$ systems was successfully described with the $\mathrm{CD}$ model using only the experimental $\mathrm{PO}_{4}$ adsorption data for parametrization. The $\mathrm{CD}$ coefficients of the $\mathrm{CO}_{3}$ surfaces complexes were derived independently from the MO/DFT optimized geometries. Our study provides insights into the surface speciation of $\mathrm{CO}_{3}$ that are consistent with the state-of-the-art knowledge of the mineral and surface structure of $\mathrm{Fh} . \mathrm{CO}_{3}$ is predominantly bound as an inner-sphere bidentate (doublecorner) complex. At high $\mathrm{CO}_{3}$ and/or $\mathrm{PO}_{4}$ loading and a high $\mathrm{Na}^{+}$concentration, this $\equiv(\mathrm{FeO})_{2} \mathrm{CO}$ complex interacts with $\mathrm{Na}^{+}$forming a ternary $\equiv(\mathrm{FeO})_{2} \mathrm{CO} \cdots \mathrm{Na}^{+}$complex in which $\mathrm{Na}^{+}$most likely forms an ion pair with the adsorbed $\mathrm{CO}_{3}$. At high $\mathrm{CO}_{3}$ loading, an additionally surface complex is formed that may be an inner-sphere monodentate complex $\left(\equiv \mathrm{FeOCO}_{2}\right.$ ).

We have shown that the $\mathrm{CD}$ model, only parametrized with the $\mathrm{PO}_{4}$ adsorption data from the $\mathrm{CO}_{3}-\mathrm{PO}_{4}$ competition experiments, can predict the experimental adsorption of $\mathrm{CO}_{3}$ in monocomponent systems with $\mathrm{CO}_{3[\mathrm{~T}]}$ levels that are relevant in the natural environment (soil, river, groundwater, and seawater). The adsorption of $\mathrm{CO}_{3}$ in the monocomponent systems reaches a maximum at $\mathrm{pH} \sim 6.5$ in full agreement with literature results and is thermodynamically consistent with the surface speciation derived. Our CD modeling demonstrates that the $\mathrm{CO}_{3}$ surface speciation is mainly governed by effects of charge, particularly acting on the potential of the inner Stern layer. Change in environmental conditions such as $\mathrm{pH}$, ionic strength, and concentration of competitive anions will change the relative distribution over the different $\mathrm{CO}_{3}$ surface species.

Finally, it is shown that our $\mathrm{CD}$ model can predict very well the measured adsorption isotherm of $\mathrm{PO}_{4}$ in Fh systems with $0.5 \mathrm{M} \mathrm{NaHCO}_{3}$ at high $\mathrm{pH}$. In comparison with goethite, $\mathrm{CO}_{3}$ has a significantly higher adsorption affinity to $\mathrm{Fh}$, which leads to a marked decrease in the high affinity character of the adsorption isotherm of $\mathrm{PO}_{4}$ in $0.5 \mathrm{M} \mathrm{NaHCO}_{3}$. The higher adsorption of $\mathrm{CO}_{3}$ to $\mathrm{Fh}$ is particularly evident at high $\mathrm{pH}$ values, and it is related to the enhanced interaction of $\mathrm{Na}^{+}$with the $\mathrm{BC}$ complex forming $\mathrm{BCNa}$. The parametrized $\mathrm{CO}_{3}-\mathrm{PO}_{4}$ interaction can be used to interpret the equilibration data of soil extractions in $0.5 \mathrm{M} \mathrm{NaHCO}_{3}$ solution to reveal RSA, using $\mathrm{Fh}$ as reference material for the natural oxide fraction. A consistent determination of the RSA may improve the prediction of the adsorption behavior of nutrients and pollutants in environmental samples with surface complexation modeling.

\section{ASSOCIATED CONTENT}

\section{Supporting Information}

The Supporting Information is available free of charge on the ACS Publications website at DOI: 10.1021/acsearthspacechem. 8 b00160.

Experimental conditions of the batch experiments (1), Additional phosphate adsorption experiments (2), Thermodynamic databases used in the $C D$ modeling (3), Evaluation of carbonate adsorption parameters at different scales (4), Aqueous complex formation of $\mathrm{Fe}(\mathrm{III})$-carbonates (5), Normalized competitive adsorption isotherms (6), Adsorption isotherms: carbonate surface speciation (7), Adsorption data of carbonate from literature (8), Bond length and Brown bond valence concept (9), Effect of phosphate adsorption on the surface charge of ferrihydrite (10) (PDF)

\section{AUTHOR INFORMATION}

\section{Corresponding Author}

*E-mail address: juan.mendezfernandez@wur.nl.

ORCID

Juan C. Mendez: 0000-0002-1658-400X

\section{Notes}

The authors declare no competing financial interest.

\section{ACKNOWLEDGMENTS}

We highly appreciate the work of Jelle Jansen in collecting part of the $\mathrm{CO}_{3}-\mathrm{PO}_{4}$ competition data. We are also grateful for the accurate and attentive work regarding the sample analysis by Peter Nobels and Johan Uijtenbroek, from the Chemistry and Biology Soil Laboratory (CBLB). The grant provided by the University of Costa Rica (UCR) to the first author is gratefully acknowledged.

\section{REFERENCES}

(1) Hochella, M. F.; Lower, S. K.; Maurice, P. A.; Penn, R. L.; Sahai, N.; Sparks, D. L.; Twining, B. S. Nanominerals, mineral nanoparticles, and earth systems. Science (Washington, DC, U. S.) 2008, 319 (5870), $1631-1635$.

(2) van der Zee, C.; Roberts, D. R.; Rancourt, D. G.; Slomp, C. P. Nanogoethite is the dominant reactive oxyhydroxide phase in lake and marine sediments. Geology 2003, 31 (11), 993-996.

(3) Hiemstra, T.; Antelo, J.; van Rotterdam, A. M. D.; van Riemsdijk, W. H. Nanoparticles in natural systems II: The natural oxide fraction at interaction with natural organic matter and phosphate. Geochim. Cosmochim. Acta 2010, 74 (1), 59-69.

(4) Wang, X.; Kubicki, J. D.; Boily, J. F.; Waychunas, G. A.; Hu, Y.; Feng, X.; Zhu, M. Binding geometries of silicate species on ferrihydrite surfaces. ACS Earth Sp. Chem. 2018, 2 (2), 125-134. 
(5) Hiemstra, T. Ferrihydrite interaction with silicate and competing oxyanions: Geometry and hydrogen bonding of surface species. Geochim. Cosmochim. Acta 2018, 238, 453-476.

(6) Liu, J.; Zhu, R.; Liang, X.; Ma, L.; Lin, X.; Zhu, J.; He, H.; Parker, S. C.; Molinari, M. Synergistic adsorption of $\mathrm{Cd}(\mathrm{II})$ with sulfate/phosphate on ferrihydrite: An in situ ATR-FTIR/2D-COS study. Chem. Geol. 2018, 477, 12-21.

(7) Zhang, Y.; Wu, B.; Xu, H.; Liu, H.; Wang, M.; He, Y.; Pan, B. Nanomaterials-enabled water and wastewater treatment. NanoImpact 2016, 3-4, 22-39.

(8) Xu, P.; Zeng, G. M.; Huang, D. L.; Feng, C. L.; Hu, S.; Zhao, M. H.; Lai, C.; Wei, Z.; Huang, C.; Xie, G. X.; et al. Use of iron oxide nanomaterials in wastewater treatment: A review. Sci. Total Environ. 2012, 424, 1-10.

(9) Gora, S.; Liang, R.; Zhou, Y. N.; Andrews, S. Settleable engineered titanium dioxide nanomaterials for the removal of natural organic matter from drinking water. Chem. Eng. J. 2018, 334, 638649.

(10) Michel, F. M.; Ehm, L.; Antao, S. M.; Lee, P. L.; Chupas, P. J.; Liu, G.; Strongin, D. R.; Schoonen, M. A. A.; Phillips, B. L.; Parise, J. B. The structure of ferrihydrite, a nanocrystalline material. Science 2007, 316 (5832), 1726-1729.

(11) Hiemstra, T. Surface and mineral structure of ferrihydrite. Geochim. Cosmochim. Acta 2013, 105, 316-325.

(12) Jambor, J. L.; Dutrizac, J. E. Occurrence and constitution of natural and synthetic ferrihydrite, a widespread iron oxyhydroxide. Chem. Rev. 1998, 98 (7), 2549-2586.

(13) Guo, H.; Barnard, A. S. Naturally occurring iron oxide nanoparticles: morphology, surface chemistry and environmental stability. J. Mater. Chem. A 2013, 1 (1), 27-42.

(14) Hiemstra, T. Formation, stability, and solubility of metal oxide nanoparticles: Surface entropy, enthalpy, and free energy of ferrihydrite. Geochim. Cosmochim. Acta 2015, 158, 179-198.

(15) Stumm, W.; Morgan, J. J. Aquatic chemistry: chemical equilibria and rates in natural waters; John Wiley \& Sons, 2012; Vol. 126.

(16) Villalobos, M.; Leckie, J. O. Carbonate adsorption on goethite under closed and open $\mathrm{CO} 2$ conditions. Geochim. Cosmochim. Acta 2000, 64 (22), 3787-3802.

(17) Hausner, D. B.; Bhandari, N.; Pierre-Louis, A. M.; Kubicki, J. D.; Strongin, D. R. Ferrihydrite reactivity toward carbon dioxide. J. Colloid Interface Sci. 2009, 337 (2), 492-500.

(18) Taifan, W.; Boily, J.-F.; Baltrusaitis, J. Surface chemistry of carbon dioxide revisited. Surf. Sci. Rep. 2016, 71 (4), 595-671.

(19) Ostergren, J. D.; Brown, G. E.; Parks, G. A.; Persson, P. Inorganic ligand effects on $\mathrm{Pb}(\mathrm{II})$ sorption to goethite $(\alpha-\mathrm{FeOOH})$ II. Sulfate. J. Colloid Interface Sci. 2000, 225 (2), 483-493.

(20) Wazne, M.; Korfiatis, G. P.; Meng, X. Carbonate effects on hexavalent uranium adsorption by iron oxyhydroxide. Environ. Sci. Technol. 2003, 37 (16), 3619-3624.

(21) Hiemstra, T.; Van Riemsdijk, W. H.; Rossberg, A.; Ulrich, K.-U. A surface structural model for ferrihydrite II: Adsorption of uranyl and carbonate. Geochim. Cosmochim. Acta 2009, 73 (15), 4437-4451.

(22) Appelo, C. A. J.; Van Der Weiden, M. J. J.; Tournassat, C.; Charlet, L. Surface complexation of ferrous iron and carbonate on ferrihydrite and the mobilization of arsenic. Environ. Sci. Technol. 2002, 36 (14), 3096-3103.

(23) Stachowicz, M.; Hiemstra, T.; Van Riemsdijk, W. H. Arsenicbicarbonate interaction on goethite particles. Environ. Sci. Technol. 2007, 41 (16), 5620-5625.

(24) Zachara, J. M.; Girvin, D. C.; Schmidt, R. L.; Resch, C. T. Chromate adsorption on amorphous iron oxyhydroxide in the presence of major groundwater ions. Environ. Sci. Technol. 1987, 21 (6), 589-594.

(25) van Geen, A.; Robertson, A. P.; Leckie, J. O. Complexation of carbonate species at the goethite surface: Implications for adsorption of metal ions in natural waters. Geochim. Cosmochim. Acta 1994, 58 (9), 2073-2086.

(26) Brechbühl, Y.; Christl, I.; Elzinga, E. J.; Kretzschmar, R. Competitive sorption of carbonate and arsenic to hematite:
Combined ATR-FTIR and batch experiments. J. Colloid Interface Sci. 2012, 377 (1), 1-18.

(27) Biswas, A.; Gustafsson, J. P.; Neidhardt, H.; Halder, D.; Kundu, A. K.; Chatterjee, D.; Berner, Z.; Bhattacharya, P. Role of competing ions in the mobilization of arsenic in groundwater of Bengal Basin: Insight from surface complexation modeling. Water Res. 2014, 55, 30-39.

(28) Peter, A.; Lamert, H.; Beyer, M.; Hornbruch, G.; Heinrich, B.; Schulz, A.; Geistlinger, H.; Schreiber, B.; Dietrich, P.; Werban, U.; et al. Investigation of the geochemical impact of $\mathrm{CO} 2$ on shallow groundwater: design and implementation of a $\mathrm{CO} 2$ injection test in Northeast Germany. Environ. Earth Sci. 2012, 67 (2), 335-349.

(29) Rahnemaie, R.; Hiemstra, T.; van Riemsdijk, W. H. Carbonate adsorption on goethite in competition with phosphate. J. Colloid Interface Sci. 2007, 315 (2), 415-425.

(30) Flower, H.; Rains, M.; Lewis, D.; Zhang, J.-Z.; Price, R. Control of phosphorus concentration through adsorption and desorption in shallow groundwater of subtropical carbonate estuary. Estuarine, Coastal Shelf Sci. 2016, 169, 238-247.

(31) Hiemstra, T.; Antelo, J.; Rahnemaie, R.; van Riemsdijk, W. H. Nanoparticles in natural systems I: The effective reactive surface area of the natural oxide fraction in field samples. Geochim. Cosmochim. Acta 2010, 74 (1), 41-58.

(32) Hiemstra, T.; Van Riemsdijk, W. H. A surface structural approach to ion adsorption: The charge distribution (CD) model. J. Colloid Interface Sci. 1996, 179 (2), 488-508.

(33) Michel, F. M.; Barron, V.; Torrent, J.; Morales, M. P.; Serna, C. J.; Boily, J.-F.; Liu, Q.; Ambrosini, A.; Cismasu, A. C.; Brown, G. E. Ordered ferrimagnetic form of ferrihydrite reveals links among structure, composition, and magnetism. Proc. Natl. Acad. Sci. U. S. A. 2010, 107 (7), 2787-2792.

(34) Brown, I. D.; Altermatt, D. Bond-valence parameters obtained from a systematic analysis of the inorganic crystal structure database. Acta Crystallogr., Sect. B: Struct. Sci. 1985, 41 (4), 244-247.

(35) Brown, I. D. Recent developments in the methods and applications of the bond valence model. Chem. Rev. 2009, 109 (12), $6858-6919$.

(36) Hiemstra, T.; Van Riemsdijk, W. H. A surface structural model for ferrihydrite I: Sites related to primary charge, molar mass, and mass density. Geochim. Cosmochim. Acta 2009, 73 (15), 4423-4436.

(37) Hiemstra, T.; Zhao, W. Reactivity of ferrihydrite and ferritin in relation to surface structure, size, and nanoparticle formation studied for phosphate and arsenate. Environ. Sci.: Nano 2016, 3, 1265-1279.

(38) Grivé, M.; Duro, L.; Bruno, J. Fe(III) mobilisation by carbonate in low temperature environments: Study of the solubility of ferrihydrite in carbonate media and the formation of $\mathrm{Fe}$ (III) carbonate complexes. Appl. Geochem. 2014, 49, 57-67.

(39) Hiemstra, T.; Van Riemsdijk, W. H. On the relationship between charge distribution, surface hydration, and the structure of the interface of metal hydroxides. J. Colloid Interface Sci. 2006, 301 (1), $1-18$.

(40) Keizer, M. G.; van Riemsdijk, W. H.ECOSAT, Equilibrium Calculation of Speciation and Transport. Technical Report. Department of Soil Quality. Wageningen Univeristy; 1998.

(41) Kinniburgh, D. G. Fit, Technical Report WD/93/23; Keyworth, Great Britain, 1993.

(42) Rahnemaie, R.; Hiemstra, T.; Van Riemsdijk, W. H. Geometry, charge distribution, and surface speciation of phosphate on goethite. Langmuir 2007, 23 (7), 3680-3689.

(43) Bruno, J.; Stumm, W.; Wersin, P.; Brandberg, F. On the influence of carbonate in mineral dissolution: I. The thermodynamics and kinetics of hematite dissolution in bicarbonate solutions at $\mathrm{T}=$ $25^{\circ} \mathrm{C}$. Geochim. Cosmochim. Acta 1992, 56 (3), 1139-1147.

(44) Hummel, W.; Bruno, J.; Stumm, W.; Wersin, P.; Brandberg, F. Comment on "On the influence of carbonate in mineral dissolution: 1. The thermodynamics and kinetics of hematite dissolution in bicarbonate solutions at $\mathrm{T}=25^{\circ} \mathrm{C}$ " by. Geochim. Cosmochim. Acta 2000, 64 (12), 2167-2171. 
(45) Antelo, J.; Fiol, S.; Pérez, C.; Mariño, S.; Arce, F.; Gondar, D.; López, R. Analysis of phosphate adsorption onto ferrihydrite using the CD-MUSIC model. J. Colloid Interface Sci. 2010, 347 (1), 112-119.

(46) Stachowicz, M.; Hiemstra, T.; van Riemsdijk, W. H. Multicompetitive interaction of As(III) and As(V) oxyanions with $\mathrm{Ca} 2+$, $\mathrm{Mg} 2+, \mathrm{PO} 3-4$, and $\mathrm{CO} 2-3$ ions on goethite. J. Colloid Interface Sci. 2008, 320 (2), 400-414.

(47) Gu, C.; Wang, Z.; Kubicki, J. D.; Wang, X.; Zhu, M. X-ray absorption spectroscopic quantification and speciation modeling of sulfate adsorption on ferrihydrite surfaces. Environ. Sci. Technol. 2016, 50 (15), 8067-8076.

(48) Arai, Y.; Sparks, D. L. ATR-FTIR spectroscopic investigation on phosphate adsorption mechanisms at the ferrihydrite-water interface. J. Colloid Interface Sci. 2001, 241 (2), 317-326.

(49) Mallet, M.; Barthélémy, K.; Ruby, C.; Renard, A.; Naille, S. Investigation of phosphate adsorption onto ferrihydrite by $\mathrm{X}$-ray Photoelectron Spectroscopy. J. Colloid Interface Sci. 2013, 407, 95101.

(50) Goldberg, S.; Johnston, C. T. Mechanisms of arsenic adsorption on amorphous oxides evaluated using macroscopic measurements, vibrational spectroscopy, and surface complexation modeling. $J$. Colloid Interface Sci. 2001, 234 (1), 204-216.

(51) Villalobos, M.; Leckie, J. O. Surface complexation modeling and FTIR study of carbonate adsorption to goethite. J. Colloid Interface Sci. 2001, 235 (1), 15-32.

(52) Wijnja, H.; Schulthess, C. P. Carbonate adsorption mechanism on goethite studied with ATR - FTIR, DRIFT, and proton coadsorption measurements. Soil Sci. Soc. Am. J. 2001, 65 (2), 324-330.

(53) Su, C.; Suarez, D. L. In situ infrared speciation of absorbed carbonate on aluminum and iron oxides. Clays Clay Miner. 1997, 45, $814-825$.

(54) Goldsmith, J. A.; Ross, S. D. Factors affecting the infra-red spectra of planar anions with D3h symmetry-IV The vibrational spectra of some complex carbonates in the region $4000-400 \mathrm{~cm}-1$. Spectrochim. Acta Part A Mol. Spectrosc. 1968, 24 (8), 993-998.

(55) Hiemstra, T.; Rahnemaie, R.; Van Riemsdijk, W. H. Surface complexation of carbonate on goethite: IR spectroscopy, structure and charge distribution. J. Colloid Interface Sci. 2004, 278 (2), 282290.

(56) Bargar, J. R.; Kubicki, J. D.; Reitmeyer, R.; Davis, J. A. ATRFTIR spectroscopic characterization of coexisting carbonate surface complexes on hematite. Geochim. Cosmochim. Acta 2005, 69 (6), $1527-1542$.

(57) Kubicki, J. D.; Kwon, K. D.; Paul, K. W.; Sparks, D. L. Surface complex structures modelled with quantum chemical calculations: Carbonate, phosphate, sulphate, arsenate and arsenite. Eur. J. Soil Sci. 2007, 58 (4), 932-944.

(58) Capewell, S. G.; Buchner, R.; Hefter, G.; May, P. M. Dielectric relaxation of aqueous $\mathrm{Na} 2 \mathrm{CO} 3$ solutions. Phys. Chem. Chem. Phys. 1999, 1 (8), 1933-1937.

(59) Rudolph, W. W.; Irmer, G.; Königsberger, E. Speciation studies in aqueous $\mathrm{HCO}_{3}{ }^{-}-\mathrm{CO}_{3}{ }^{2-}$ solutions. A combined Raman spectroscopic and thermodynamic study. Dalt. Trans. 2008, 0 (7), 900-908.

(60) Johnston, C. P.; Chrysochoou, M. Mechanisms of chromate, selenate, and sulfate adsorption on Al-substituted ferrihydrite: Implications for ferrihydrite surface structure and reactivity. Environ. Sci. Technol. 2016, 50 (7), 3589-3596.

(61) Wang, X.; Wang, Z.; Peak, D.; Tang, Y.; Feng, X.; Zhu, M. Quantification of coexisting inner- and outer-sphere complexation of sulfate on hematite surfaces. ACS Earth Sp. Chem. 2018, 2 (4), 387398.

(62) Baltrusaitis, J.; Schuttlefield, J. D.; Zeitler, E.; Jensen, J. H.; Grassian, V. H. Surface reactions of carbon dioxide at the adsorbed water-oxide interface. J. Phys. Chem. C 2007, 111 (40), 14870-14880.

(63) Baltrusaitis, J.; Schuttlefield, J.; Zeitler, E.; Grassian, V. H. Carbon dioxide adsorption on oxide nanoparticle surfaces. Chem. Eng. J. 2011, 170 (2-3), 471-481.
(64) Zheng, L.; Apps, J. A.; Spycher, N.; Birkholzer, J. T.; Kharaka, Y. K.; Thordsen, J.; Beers, S. R.; Herkelrath, W. N.; Kakouros, E.; Trautz, R. C. Geochemical modeling of changes in shallow groundwater chemistry observed during the MSU-ZERT CO2injection experiment. Int. J. Greenhouse Gas Control 2012, 7, 202-217.

(65) Trautz, R. C.; Pugh, J. D.; Varadharajan, C.; Zheng, L.; Bianchi, M.; Nico, P. S.; Spycher, N. F.; Newell, D. L.; Esposito, R. A.; Wu, Y.; et al. Effect of dissolved $\mathrm{CO} 2$ on a shallow groundwater system: A controlled release field experiment. Environ. Sci. Technol. 2013, 47 (1), 298-305.

(66) Tsakiroglou, C. D.; Terzi, K.; Aggelopoulos, C.; Theodoropoulou, M. CO2-induced release of copper and zinc from model soil in water. Int. J. Greenhouse Gas Control 2018, 76, 150-157.

(67) Perona, M. J.; Leckie, J. O. Proton stoichiometry for the adsorption of cations on oxide surfaces. J. Colloid Interface Sci. 1985, $106(1), 64-69$.

(68) Rietra, R. P. J. J.; Hiemstra, T.; Van Riemsdijk, W. H. Electrolyte anion affinity and its effect on oxyanion adsorption on goethite. J. Colloid Interface Sci. 2000, 229 (1), 199-206.

(69) Olsen, S. R.; Cole, C. V.; Watanabe, F. S.; Dean, L. A. Estimation of available phosphorous in soils by extraction with sodium bicarbonate; 1954.

(70) Barrow, N. J.; Shaw, T. C. Sodium bicarbonate as an extractant for soil phosphate, I. Separation of the factors affecting the amount of phosphate displaced from soil from those affecting secondary adsorption. Geoderma 1976, 16 (2), 91-107. 